\title{
Does selective fishing conserve community biodiversity? Predictions from a length-based multispecies model
}

\author{
Marie-Joëlle Rochet ${ }^{1,{ }^{*}}$, Jeremy S. Collie ${ }^{2}$, Simon Jennings ${ }^{3}$ and Stephen J. Hall ${ }^{4}$ \\ ${ }^{1}$ IFREMER, B.P. 21105, 44311 NANTES CEDEX 03, France \\ ${ }^{2}$ Graduate School of Oceanography, University of Rhode Island, USA \\ ${ }^{3}$ Centre for Environment, Fisheries \& Aquaculture Science, UK \\ ${ }^{4}$ WorldFish Center, Malaysia \\ *: Corresponding author: Marie-Joëlle Rochet, Tel +33 2403741 21. Fax +33 240374075 . email \\ address : mjrochet@ifremer.fr
}

\begin{abstract}
This study challenges the widely held view that improved fisheries selectivity would always help to maintain marine biodiversity. Using a length-based multi-species model, we investigate the effects of selective versus nonselective fishing on fish communities. Both size and species selectivity are examined, and fishing effects on biodiversity are measured with three indices: (i) evenness, (ii) the number of collapsed species, and (iii) an index of size diversity. The model is parameterized for the Georges Bank and North Sea fish communities. The results suggest that there is no "optimal" size selectivity to maintain biodiversity: the effects of each exploitation pattern depend on the selectivity of the gear (i.e., the shape of the selection curve) relative to the available sizes. Catching a narrow range of species almost always reduced evenness and species richness more than taking the same catch from a broader range of species. In summary, neither selective nor nonselective fishing can be said to be generally preferable for conserving biodiversity; the outcome depends on the particular species composition and size structure of the community. Advice intended to inform management will need to be based on clear definitions of biodiversity, and unambiguous management objectives for biodiversity and the fishery.
\end{abstract}

Résumé : Cette étude remet en cause l'idée répandue qu'une amélioration de la sélectivité des pêches aiderait à protéger la biodiversité marine. Un modèle multi-spécifique en longueur est utilisé pour examiner les effets de pêches sélectives ou non sur des communautés de poissons. La sélectivité peut concerner soit la taille soit les espèces, et les effets de la pêche sont mesurés par trois indices : l'équitabilité, le nombre d'espèces surexploitées, et un indice de diversité des tailles. Le modèle est paramétré pour les communautés du Banc George et de la mer du Nord. II n'y a pas de sélectivité par taille qui conserve mieux la biodiversité dans tous les cas : le meilleur patron d'exploitation dépend de la sélectivité de l'engin (c'est-à-dire, la forme de la courbe de sélection) par rapport aux tailles disponibles. Pour ce qui concerne la sélectivité par espèce, la sélection d'un petit nombre d'espèces réduit presque toujours davantage l'équitabilité et la richesse spécifique que si la même biomasse est prise en capturant toutes les espèces. En résumé, pêche sélective ou équitable ne peuvent pas être généralement considérées comme mieux à même de préserver la biodiversité : le résultat dépend de la composition spécifique et de la structure en taille de la communauté. Tout avis pour la gestion devra reposer sur des définitions claires de la biodiversité et des objectifs de gestion pour cette dernière et pour les pêcheries. 


\section{Introduction}

Fishing gears are not perfectly selective; they generally catch a wider range of species and sizes of animals than intended. Part of the resulting by-catch can be landed and marketed, but there are two broad categories of unwanted by-catch that are usually discarded dead or dying: large-sized vertebrates such as turtles, dolphins or sharks, which may be 'charismatic' or threatened, or both; and low-valued or prohibited size-ranges and species of fish. Both categories of by-catch are the subject of increasing concern, in both the public and the scientific community (Hall 1996, Lewison et al. 2004).

Avoiding by-catch requires more selective fishing and improving selectivity is seen as an important tool to protect non-target and vulnerable species (Pikitch et al. 2004) and to rebuild marine ecosystems (Worm et al. 2009). Gear technologists generally see their goal as 'perfect gear selectivity' (Broadhurst 2008). "Improving selectivity" is generally understood as both achieving a 'cleaner' catch of the target species or size, and targeting larger sizes or species with a higher commercial value. Two types of modifications are used to change fishing selectivity, those that exploit differences in behavior among species, thus improving species-selectivity; and those that mechanically sieve organisms according to their size and change size-selectivity (Broadhurst 2000).

While improved selectivity can help to balance exploitation rates with the productivity and abundance of component populations in mixed fisheries, improved selectivity can also lead to greater contrasts in production or biomass among components of the food web. These changes will modify food-web interactions, so it is necessary to consider whether the modified interactions would support or compromise intended management objectives. There is growing evidence that selective exploitation of species in food webs has led to changes in prey, predator or competitor species. For example, changes in food webs have followed the depletion of apex predators (Polovina et al. 2009), intermediate consumers (Bundy et al. 2009), whales (Springer et al. 2003) and forage fish (Hjermann et al. 2004). Thus, if an objective of management is to maintain the structure and function of ecosystems, then more selective fishing may not support this objective (Hall 1996, Zhou 2008).

With the widespread adoption of an Ecosystem Approach to Fisheries, management authorities are starting to define objectives for biodiversity. Biodiversity, in the broadest sense, is the variety, quantity and distribution of life, but relatively few aspects of biodiversity have been used as management objectives (Greenstreet 2008), with the main focus on the population status of vulnerable species that are impacted by fisheries (Lewison et al. 2004). Gear technology (Jennings and Revill 2007), combinations of gears with different selectivities (Hinke et al. 2004) or spatial management approaches (Branch and Hilborn 2008, Pikitch et al. 2004) have been proposed to reduce mortality rates on vulnerable species. However, little has been done to consider options for more effective management of other aspects of biodiversity that might be considered as management targets. These targets include various aspects of species diversity within communities, such as evenness and total species numbers, all of which are closely related to ecosystem functioning (Purvis and Hector 2000). So how selectively should we harvest our oceans, if we are to conserve these aspects of biodiversity? The answer to this question requires, among other things, an assessment of the effect of selective fishing on marine community biodiversity. Here, we aim to develop a general, model-based comparison of the effects of changing the selectivity and rates of fishing on biodiversity. Both the choice of target and the degree of selectivity interact to determine the effect. In simulations with a size-based model, it has been predicted that selectively fishing a narrow size-range creates instability in the biomass spectrum and decreases size-diversity, while unselective fishing does not (Rochet et al. 2009, Rochet and Benoît Submitted). This effect is more pronounced when larger rather than smaller sizes are selectively fished. However, this size-based approach ignored that species life histories may make a difference in population and food web impacts (Schindler et al. 2002). Moreover, it does not consider the consequences of fishing selectivity on stock abundances, nor on other 
facets of species diversity. To predict the effects of size- or species-selectivity on community biodiversity, a model incorporating both size and species identity is required.

To mimic the community responses to fishing we parameterize an existing multi-species length-based model (Hall et al. 2006) with the species life histories and diet matrices for (1) Georges Bank, in the northwest Atlantic, and (2) the North Sea. Fishing effects on species diversity are measured by indices of richness and evenness and one that describes size diversity. We use size diversity because body size is closely related to many ecological functions (Woodward et al. 2005) and the diversity in size structure may provide one proxy for functional diversity. To describe the more social and economic consequences for fisheries, we also report the predicted effects of fishing on the catch weight and value.

When comparing selectivity patterns, one challenge is to decide which fishing pressures are comparable. Thus, in addition to comparing fishing effects at various mortality rates, we also compare them for a given catch level, based on weight or value. Here, we first describe the model, parameterization and validation criteria. Second, we present fishing scenarios based on size or species selectivity. Third, we define the community metrics used to gauge fishing effects on biodiversity and catch. Fourth, we present simulation results, and examine whether they are similar across the two communities. Finally, we discuss how these results might influence advice on developing exploitation strategies to meet specified management objectives for biodiversity.

\section{Methods}

\subsection{Community model}

A length-based multispecies model (LeMANS) (Hall et al. 2006) was used to describe the population dynamics of 21 species with defined life-histories, structured in fifteen $10-\mathrm{cm}$ length classes. In this model, animals grow towards an asymptotic size following the von Bertalanffy growth model, and reproduce according to a Ricker stock-recruit relationship. Mortality includes three components: (1) non-predation mortality (M1) is a U-shaped function of length; (2) predation mortality (M2) depends on the predator-prey size ratio, predator abundance (with a Holling type-II functional response), and a diet matrix that describes who eats whom; (3) fishing mortality $(F)$ depends both on species (some species are fished and others are not) and size, based on a logistic selection curve. In this application of the model we also used a normal selection curve (see below).

To reduce predation mortality on the smallest size class, two refinements were made to the predation component of the length-based model in this study. The parameters of the predator size-preference function were changed from $\mu=-3.5, \sigma=1$ (Hall et al. 2006, Fig. 1b) to $\mu=0.5, \sigma=2$. The result is a broader curve with preference for slightly larger sizes. These parameters give a preferred prey: predator weight ratio of 1:33, which is comparable with that measured in empirical feeding studies (Floeter and Temming 2005).

The equation for predation mortality contained a term "other food" to account for the nonmodeled prey species in the fish diets (Hall et al. 2006, Equ. 8). The model dynamics were found to be very sensitive to the amount of "other food": too little and some prey species would go extinct; too much and predation mortality on the modeled prey species was negligible. To remove this sensitivity to other food, we introduced a size-structured "forage species" to represent small fish and invertebrates in the smallest size classes, in which predation mortality is the highest. The generic life-history parameters of the forage species were patterned after the smallest fish species in the community (Table 1). The Ricker productivity parameter $(\alpha)$ was set at 400 , a high value that ensured a high biomass of forage species that would not be depleted by predation. All predator species in the model were also assumed to eat the forage species, which were not fished. 


\subsection{Model parameterization and validation}

\subsubsection{Georges Bank}

The parameterization used in Hall et al. (2006) was unchanged, except for the parameters of the stock-recruit relationship, which were recalculated from updated abundance data. Because stock-recruit relationships do not exist for most of the 21 species, we used a metaanalytic approach, whereby the density-dependent parameter of the stock-recruit relationship $(\beta)$ was related to the maximum spawning stock biomass of each species (Hall et al. 2006, Fig. 1b). In this parameterization we calculated the maximum biomass values from the Georges Bank trawl-survey data that were analyzed by Steele et al. (2007). We selected the decade from 1963-1972 as representing lower fishing mortality rates than the later period of heavy exploitation. To guard against extreme values, we chose the $90 \%$ percentile, which means that we selected the $2^{\text {nd }}$ highest biomass value for each species between 1963-1972. Updated maximum spawning biomass $\left(S_{\max }\right)$ ranged from 0.4 to 250 instead of 10 to 465 thousand tonnes; $S_{\max }$ of the forage species was set at $5 \mathrm{Mt}$, the smallest value that prevents prey species from collapsing with no fishing.

\subsubsection{North Sea}

Life-history parameters (Table 1) of 21 fish species in the North Sea and their corresponding diet matrix (Table 2) were assembled from published sources. The model comprised $1810-$ $\mathrm{cm}$ length classes to accommodate the asymptotic length of pollock Pollachius virens (Table 1 , North American common names are used for consistency with the Georges Bank fish community). Estimates of $\beta$, the density-dependent stock recruitment parameter, were derived with the meta-analytical approach described above (Hall et al. 2006). The maximum spawning-stock biomass from 1980-2004 was derived from a combination of stockassessments and trawl-survey data for non-assessed species. Stock assessments were available for 9 of the 21 species. For the remaining species, biomass estimates were taken from the International Bottom Trawl Survey (Quarter 1) and adjusted for species-specific catchability (Table 1). For the North Sea, $L_{\text {mat }}$ is the length of full maturity, not $50 \%$ maturity. Lacking a maturity ogive for the North Sea fishes, we set the slope of the maturity ogive to a high value $(\kappa=10)$ for all species to create "knife-edge" maturity. Maximum spawning biomass $\left(S_{\max }\right)$ of the forage species was set at $50 \mathrm{Mt}$, reflecting the larger area of the North Sea and greater fish biomass compared with Georges Bank.

The distribution of asymptotic length $\left(L_{\infty}\right)$ and growth coefficients $(k)$ across species corresponds with the relationship expected from life-history theory (Fig. 1) (Gislason et al. 2010). In the North Sea the community biomass is concentrated in small- and intermediatesized species $(<70 \mathrm{~cm})$ while Georges Bank biomass is dominated by intermediate- and larger-sized species. The 21 species included in LeMANS dominate biomass in the whole communities. The difference in size distributions is also a characteristic of the full Georges Bank and North Sea fish communities (Collie and Rochet 2010).

\subsubsection{Key-run specification}

Key-runs were created with six rates of fishing mortality, $F_{\text {full, }}$ on all fished species from 0 to 1. The parameterization that best mimicked the effects of fishing at the community level was selected based on four criteria. (1) Comparing the total biomass of the fish community over a range of fishing mortality with survey-based biomass estimates. (2) Comparing biomass ranked by species (which is related to evenness), estimated with LeMANS with $F_{\text {full }}=0.2$, with ranked biomass from the survey. This is an internal test of consistency because the survey biomass estimates were used to derive the stock-recruit $\beta$ parameter. (3) Comparing the slopes of size spectra estimated with the model with the slopes of survey-derived size spectra. (4) Comparing estimates of predation mortality (M2) from LeMANS with the M2 estimates of selected prey species from Multispecies Virtual Population Analysis (MSVPA). We compared the average $M 2$ for ages 0-1 from MSVPA to the annual $M 2$ averaged over the corresponding length range in LeMANS, as calculated from the von Bertalanffy growth parameters. 


\subsection{Fishing selectivity}

The effects of size- and species-selectivity were investigated separately. Fishing mortality in the model depends on both size and species independently: $F_{i, l}=F_{\text {full }} \phi_{i} S(I)$, where $F_{i, l}$ is fishing mortality of length class $I$ species $i, F_{\text {full }}$ is annual fishing mortality rate for a fully recruited fish, $\phi_{i}$ is a binary variable indicating whether species $i$ is fished, and $S(I)$ is a selection curve as a function of length. In the original model, size-selection was a logistic function

$$
S(l)=\frac{1}{1+\exp \left(-\eta\left(l-L_{F 50}\right)\right)}
$$

with $\eta$ a slope parameter and $L_{F 50}$ the size at $50 \%$ selection by the fishery. This selection model defines a lower bound: the larger the size at 50\% selection, the larger the bound and the more selective the fishery (Fig. 2a). We modeled a less selective fishery partly avoiding intermediate sizes with a 'medium' selection curve having a low slope. However, at the community level, an S-shaped function might not be realistic and a bell-shaped selection curve might be more representative of the multi-species catches relative to video estimates of total abundance (Wells et al. 2008). In addition, single-species logistic selection curves are often used for trawls, while bell-shaped selection curves might be more relevant for gillnets or hooks (Millar and Fryer 1999). Thus, besides the logistic selection curve, a bellshaped, normal selection curve was used:

$$
S(l)=\frac{1}{\sigma_{F} \sqrt{2 \pi}} e^{-\frac{1}{2}\left(\frac{l-\mu_{F}}{\sigma_{F}}\right)^{2}} .
$$

where $\mu_{F}$ is the target length, and $\sigma_{F}$ the width of fishing mortality at size, or inverse precision of the target. In this application, fishing intensity was divided by the maximum density for the most selective selection curve (0.0443) so that for selective fishing, fishing mortality at the target size is $F_{\text {full. }}$ Less selective fishing implied a lower peak mortality (Figure $2 b$ ) with the same cumulated $F$ over all length classes fished. Below we use the terms "S-shaped" to refer to the logistic curve and "bell-shaped" to refer to the normal selection curve.

The size-selection curves used in the model simulations were parameterized to be comparable with selection curves derived from stock assessments for a subset of the species (Fig. 2). Relative fishing mortality at age was extracted for the most recent decade and converted, with the corresponding von Bertalanffy growth parameters, to relative fishing mortality at length. For each species, either a logistic or normal curve was selected based on the best goodness-of-fit to the relative fishing mortality rates. Seven of the Georges Bank species had logistic size-selection curves (Fig. 2a). Most had relatively high slope parameters, except cod, which was more similar to a "medium" curve. The length at 50\% selection ranged from $15 \mathrm{~cm}$ for herring to $55 \mathrm{~cm}$ for cod and haddock. Spiny dogfish (not plotted) had knife-edge selection at $75 \mathrm{~cm}$. One species, white hake, had a bell-shaped selection curve that is very similar to a medium unselective curve (Fig. 2b). In the North Sea three species had S-shaped selection curves with high slope and small length at $50 \%$ selection (Fig. 2c). Five species had a bell-shaped selection curve, in which width was correlated with mode: larger species seemed to be exploited less selectively (Fig. 2d). Overall, the set of size-selection curves used in the simulations covers the range of observed selection curves.

For both logistic and normal size selection, nine contrasting scenarios of selective/unselective fishing were simulated (Table 3 ) along with a series of increasing rates of fully recruited fishing mortality. Because the selectivity curves have various shapes, however, combinations with fishing mortality will exert pressures on the community that are not directly comparable. Therefore community metrics were examined as a function of either 
$F_{\text {full }}$ or total catch, taken as a measure of fishing pressure at the community level. Total catch was measured either in weight or in value (estimated as weight multiplied by average price per pound or $\mathrm{kg}$ ). Price data were obtained for Georges Bank from Eric Thunberg (Northeast Fisheries Science Center, Woods Hole, MA, personal communication) and for the North Sea from Fabienne Daurès (Ifremer, Brest, France, personal communication) for sandeel and sprat,

and http://www.ofimer.fr/Pages/filiere/Publications ObsEco.html\#bilans annuels ofimer for the other species. In this analysis species selectivity was set as in the key-runs: there were four unfished species on Georges Bank and seven in the North Sea, including the forage species. Species selectivity was analyzed by varying the number of species fished, that is, by manipulating the $\phi_{i}$ parameters: the target set is the set of species with $\phi_{i}=1$. For these species-selection trials, the maximum fishing mortality was set at 0.4. Target sets of increasing number were created randomly; each number was repeated at least 21 times with different random sets, and the resulting distributions of community metrics were compared. The number of samples was increased until the patterns stabilized, that is, up to 250 for intermediate numbers of species (8 to 13); in these cases the number of possible sets increases exponentially (up to 350,000 for 10 and 11 species). Reference levels for community metrics in unselectively fished communities were calculated as follows: for each target number, we calculated median total catch, and identified the fishing mortality rate $\left(F^{\star}\right.$ full $)$ that would yield at least that total catch, if all species were fished. The value of each community index with all species fished at $F^{\star}$ full was then used as a reference value. In this analysis size selectivity was set as in Hall et al. (2006), so that most sizes were targeted (logistic selection curve with $L_{F 50}=25 \mathrm{~cm}$ and $\eta=0.25$ ).

\subsection{Measuring fishing effects}

Fishing effects at the community level were measured with three diversity measures, two for species diversity and one for size diversity. For measuring species diversity in simulated communities with fixed numbers of species $(N)$, richness has little meaning, but a strong reduction in population size of a given species may amount to a functional loss of that species. The change in richness was therefore described by the number of species collapsed, where "collapsed" is defined as a reduction in biomass of $90 \%$ or more from the unfished level (e.g. according to the IUCN criterion: species are listed as critically endangered if their population numbers were reduced by $90 \%$ or more over a specified timeperiod, http://www.iucnredlist.org/). In addition, a metric of the evenness of the distribution of individuals among species is needed. Simpson's reciprocal evenness index $E_{1 / D}=1 /(D N)$ was used, where Simpson's $D$ measures the probability that two random individuals belong to different species (Smith and Wilson 1996). For measuring size diversity, a similar index with size classes instead of species is inappropriate, because it does not account for size classes being ordered; so a metric including some measure of distance, like the taxonomic diversity metrics of Clarke and Warwick (1998), is required. We used average size-distance between two random individuals, giving size diversity as

$$
\Sigma=\frac{\sum_{x_{\min }}^{x_{\max }} \sum_{y_{\min }}^{y_{\max }} d(x, y) u(x) \exp (x) u(y) \exp (y) d x d y}{\sum_{x_{\min }}^{x_{\max } y_{\max }} u(x) \exp (x) u(y) \exp (y) d x d y}
$$

where $u(x)$ is the number of individuals with size $x, d(x, y)=1-\exp (-\delta|x-y|)$ measures the distance between two sizes $x$ and $y$, and $\delta$ is a shape parameter determining the rate at which the distance will reach 1 (Rochet et al. 2009, Rochet and Benoît Submitted). The size diversity of a linear size spectrum decreases as its slope decreases (as size spectra have negative slopes, this means that steeper spectra are less diverse); bumpy size spectra have lower size diversity than regular ones. 


\section{Results}

\subsection{Model key runs}

Both key-runs had acceptable levels of agreement with empirical measures of community structure (Fig. 3). The model estimates of Georges Bank biomass over a range of fishing mortality from 0.2 to 0.7 spanned the range of survey biomass, calculated either over the entire time series or for the decade 1963-1972, when fish biomass was lower (Fig. 3a). For the North Sea, total biomass of the fish community estimated with LeMANS was generally lower than the biomass of 11 commercial fish species estimated from stock assessments for the years 1983-1985 (Sparholt 1990). The estimates are in better agreement for quarter 1 than quarter 3, but only for modeled fishing mortality less than 0.2 (Fig. 3a). Biomass ranked by species, estimated with LeMANS with $F_{\text {full }}=0.2$, agreed well with the survey ranked biomass (Fig. 3b). This criterion ensured that the evenness in the modeled community is similar to that in the real fish community. In the North Sea exceptions occurred for the two most (herring, sandeel) and least abundant (cuckoo ray, monkfish) species, with LeMANS predicting a more even distribution of biomass (Fig. 3b). The estimated size spectra matched the survey size spectra quite well, although in the North Sea, LeMANS slightly overestimated abundances for lengths $>25 \mathrm{~cm}$ (Fig. 3c). The estimates of predation mortality (M2) from LeMANS are the same order of magnitude as the $M 2$ estimates of six prey species from an MSVPA of the Georges Bank fish community (Tsou and Collie 2001), but they differ for particular species (Fig. 3d). For example, the M2 estimates are in good agreement for Atlantic cod, but the MSVPA estimates are considerably higher for yellowtail flounder, haddock, silver hake, and Atlantic herring. In LeMANS the selectivity for prey species depends only on their size, whereas MSVPA includes a species-preference parameter. Therefore in LeMANS it is difficult to fine-tune the $M 2$ values for particular prey species. For the North Sea, LeMANS M2 values are in good agreement for the smaller prey species (sandeel and sprat) but are lower for larger species (cod, haddock, and whiting). In any case predation mortality cannot be directly observed and these are all model estimates. In summary, the diagnostic criteria were met for both the Georges Bank and North Sea fish communities apart from minor differences in total biomass. Both key-runs were accepted as the bases for subsequent selectivity simulations.

\subsection{Size selectivity}

The effects of mortality depend on the shape of the selectivity function (Fig. 4, Table 4). On Georges Bank with a logistic selection curve, the highest catch could be obtained by the "medium" selection ogive and $F_{\text {full }}=1$, while catch peaked for $F_{\text {full }}=0.4$ when small fish were fished. With a bell-shaped selection curve, high catches were obtained regardless of selectivity when large or medium-sized fish were targeted; when the target was small, less than half the maximum catch could be obtained, and still less when fishing selectively (Fig. 4g). Evenness was little affected by targeting large fish, and decreased when fishing mortality increased if medium or small fish were targeted (Fig. 4a,e). The number of collapsed species increased when fishing mortality increased, more when small sizes were targeted, irrespective of selectivity (Fig. 4d,h). More species were collapsed with the logistic selection curve, illustrating the higher fishing pressure on the community when this model is used. Size diversity decreased when fishing pressure increased with the logistic selection curve (Fig. 4b) or when large fish were targeted (Fig. 4f), but increased with the bell-shaped selection curve when small or medium fish were targeted (Fig. 4f).

By way of contrast, in the North Sea with an S-shaped selection curve, high catches could be obtained either with a "small" or "medium" selection ogive, but catches remained low, regardless of overall fishing pressure, when large fish were targeted (Fig. 5c, Table 4). Also, when targeting large fish, total biomass and average weight (not shown) of fish in the community remained unchanged by fishing, as large sizes are mostly absent from the North 
Sea. Size diversity was highest when small fish were fished (Fig. 5b). With bell-shaped selectivity curves, maximum total catch was reached when targeting medium-sized fish unselectively; large catches could also be taken by targeting large- or medium-sized fish unselectively (Fig. $5 \mathrm{~g}$ ). Size diversity increased with increasing fishing pressure when small sizes were targeted, while it slightly decreased when larger sizes were targeted (Fig. 5f). Noticeably, evenness was always higher when fishing unselectively than selectively, irrespective of the size targeted (Fig. 5e). Evenness was highest when small fish were exploited unselectively, and lowest when small fish were exploited selectively, because in this case some species, including sandeel, herring, horse mackerel, witch flounder and plaice, were lost from the system.

These results reflect the shapes of the size spectra of the model-communities (Fig. 6): on Georges Bank there is little biomass in the small size-classes, thus selectively targeting them cannot yield a high catch. Clearly the S-shaped selection curve with a small size at $50 \%$ selection amounts to catching almost everything in the community, and the resulting fishing pressure at the community level is high; it is the only selection pattern that potentially leads to community overfishing. Size diversity decreased with increasing fishing pressure with the logistic selection curve owing to the loss of large fish (Fig. 6a) but increased with the bellshaped selection curve (Fig. 6b); the exception being when large fish were targeted. In this case, the depletion in large fishes released small fishes from predation (Fig. 6b).

The unfished model community for the North Sea was dominated by small fishes (Fig. 6c,d). Size diversity increased at high fishing pressures because the size spectrum was more regular owing to the depletion of the small-size peak (Fig. 6c). Only small catches could be taken by targeting large fish selectively, owing to the small overlap between the size spectrum and the selection curve (Fig. 6d). Targeting small sizes resulted in decreased abundance at all sizes and the spectrum became less bumpy, thus size diversity increased with increasing fishing pressure. When larger sizes were targeted size diversity decreased because the spectrum was steeper (Fig. 6d).

When community metrics were plotted against total catch, patterns depended on the ecosystem and the shape of the selection curve (Fig. 7). On Georges Bank with an Sshaped selectivity, evenness and size diversity decreased as catch increased (except with "small size selection", where a loop is observed owing to decreasing catch for high fishing mortality, Fig. 7a,b). With a bell-shaped selectivity, evenness decreased with catch, more steeply when smaller fish were targeted; non-selective exploitation of small fish resulted in the steepest decline, while non-selective exploitation of large fish led to the least change. Targeting small fish maximized size-diversity and did not yield large catches, but nonselective exploitation of medium sizes led to high catches and high size diversity (Fig. 7d). The difference in patterns is explained by the overlap between the size spectrum and the selectivity curves (Fig. 6); small sizes have together the highest species richness and a relatively low biomass. When small sizes are targeted, most of biomass in the small sizerange is removed and consequently the impact on the community is higher than for any other strategy. By contrast, in the North Sea evenness and size diversity were maximized when lightly fishing small fish (S-shaped selection curve, Fig. 7e,f). With a bell-shaped selectivity curve evenness was highest with selective exploitation patterns (targeting small or intermediate sizes), but size diversity was maximized by targeting small fish (whether selectively or not, Fig. $7 \mathrm{~g}, \mathrm{~h}$ ). Using the value of total catch instead of weight as an index of fishing pressure yielded very similar figures (Fig. S1, Supplementary material). In both communities a combination of high catches, high evenness and high size diversity was best obtained by fishing with a bell-shaped curve targeting medium-sized fish, selectively in the North Sea and unselectively on Georges Bank.

\subsection{Species selectivity}

When including the Georges Bank species randomly in the target set, diversity metrics decreased as the number of species fished increased (Fig. 8). Total catch increased monotonically as the number of species targeted increased (not shown), and as a 
consequence total biomass in the community decreased, but less steeply when fishing everything rather than a smaller target set (Fig. 8c). For a similar catch, species diversity metrics were always higher when fishing unselectively for all species rather than any set. Both evenness and the number of species collapsed seemed to be relatively insensitive to non-selective fishing up to catches of 150,000 tonnes (that is, $12.5 \%$ of total biomass in the unfished system, corresponding to subset of up to 10 species), but decreased monotonically when fishing selectively (Fig. 8a,d). Size diversity was relatively insensitive to non-selective fishing, and slightly increased when targeting small subsets up to 13 species, but the difference was small compared with sampling variability (Fig. 8b).

The general pattern was similar in the North Sea, with the following differences (Fig. 9). i) When all species were fished, the reference line showed that evenness in the community increased with total catch (because the most abundant species, sandeel and herring, were increasingly depleted). In contrast, evenness was a U-shaped function of the number of species targeted. ii) Only one species was collapsed at $F_{\text {full }}=0.4$ in the North Sea. With $F_{\text {full }}=0.8$ (not shown), the pattern was similar to Georges Bank, thereby illustrating that nonselective fishing had a lower impact than selective fishing. iii) Size diversity decreased with total catch and was always higher when fishing everything than when targeting a smaller set. Again using total value of catch rather than weight to calculate the reference level produced very similar figures (not shown).

\section{Discussion}

\subsection{Does selective fishing conserve community biodiversity?}

Fishing all species unselectively had smaller effects on the selected biodiversity metrics for the community than selectively targeting a restricted set of species, and selectively fishing large fish did not maximize biodiversity for a given level of catch weight or value. Moreover, the differential effects of fishing selectivity are larger when fishing intensity is high. The effects of size-selectivity on species- and size- diversity depended on i) the shape of the size-selection curve, and ii) the community size-structure and species composition. Our results are also conditional on the choice of diversity metrics and on adopting total catch as a measure of fishing pressure on the community.

The predicted effects of size-selectivity and target size depended on whether the sizeselection curve was S- or bell-shaped. The direction of effects and the selectivity that maximized each given metric differed among selection curves. Given the variety of predicted responses, which of the size-selection models is likely to be more realistic? These models should describe, across all species, the proportion of the available fish in each size-class that are caught. As we are focusing on multi-gear, multi-species fisheries, this proportion is not easy to determine, since the selection curves will differ among gears and species. Fishing mortality estimates from stock assessments suggest that selectivity curves for most species are S-shaped on Georges Bank and bell-shaped in the North Sea (Fig. 2), although this seems counter-intuitive because these species are caught mainly by trawl. However, fishing mortality at age (or length) might not be a good proxy for selectivity when large individuals are scarce in catch statistics. As there are few, if any, fish in the oldest age classes, they are often collapsed in a "+ group" in assessment models, and changes in fishing mortality in the largest size classes are not estimated. While we consider that the stock assessment results were the best available information to check that theoretical selection curves were correctly parameterized, they cannot be used to determine which curve is most appropriate. As a sum of species size-selection curves, the community size-selection curve would be S-shaped on Georges Bank, and a rather wide bell in the North Sea. Unfortunately these estimates were available for only a subset of the species in the model, which are themselves a small subset of the species in the actual communities. Field studies are needed to improve our knowledge of selectivity at the community scale. Obviously they will be complicated by the difficulty of 
obtaining a reliable estimate of the species and size classes available, and when several gears are used and each one catches a different part of a population or community, no one gear is likely to give a complete picture (e.g., Bellchambers and de Lestang 2005, Olin et al. 2009). Novel work is required in this field, and for now, results with both selection curves are retained.

\subsection{Modeling communities}

The predicted effects of fishing selectively were different on Georges Bank and in the North Sea. These differences can be ascribed to differences between the modeled or the actual communities, and raises the question of how well the model captures the properties of the real communities.

Species evenness was higher in the North Sea because of a less steep slope of species dominance (Fig. 3). The North Sea did not lose species as quickly, even with high fishing mortality, possibly because more of the North Sea is dominated by small- and intermediatesized species with correspondingly higher growth and reproductive rates. In contrast, intermediate- and large- sized species dominated on Georges Bank, and size diversity and average weight were higher, consistent with the biomass spectrum peaking at larger sizes. Differences in the modeled fish communities arise from the input life-history parameters (Fig. 1) and influence the response to selective fishing. With no fishing the biomass spectrum for Georges Bank peaks at $70-80 \mathrm{~cm}$, with a sub-peak at $40-50 \mathrm{~cm}$, reflecting the dominance of haddock (Fig. 6). In contrast, the unfished North Sea biomass spectrum peaks at $20-30 \mathrm{~cm}$, with a sub-peak at $60-70 \mathrm{~cm}$. This difference, which is generated by the distribution of biomass among species, determines the outcome of size-selective fishing.

The two refinements made to the LeMANS model improved its stability and realism. Increasing the preferred prey:predator weight ratio $(\mu)$ and breadth of the size-preference function $(\sigma)$ helped to stabilize the model dynamics, as would be expected from other studies (e.g., Benoît and Rochet 2004, Emmerson and Raffaelli 2004). It also reduced the predation mortality on the smallest size class because it became less vulnerable to intermediate size predators, which have high biomass. The smallest size-class is particularly vulnerable to the effects of predation because individuals grow out of it relatively quickly and it is only replenished by recruitment at the end of each year. The inclusion of an explicit forage species provided additional biomass in the smallest size classes. An advantage of this formulation is that the abundance of forage species is now dynamically linked to predator abundance (Gislason 1999) and it can be compared with empirical estimates of available food. The magnitude of maximum spawning stock biomass $S_{\max }$ assumed for the forage species is consistent with the amounts of plankton and benthos available to fish, as estimated with food-web models (Collie et al. 2009, Mackinson and Daskalov 2007). Assuming a production-to-biomass ratio of approximately 1 , we estimated similar densities of plankton and benthos biomass on Georges Bank $\left(189 \mathrm{~g} \cdot \mathrm{m}^{-2}\right)$ and the North Sea $\left(159 \mathrm{~g} \cdot \mathrm{m}^{-2}\right)$. Scaling these densities by area gives a total biomass of plankton and benthos of $7.34 \mathrm{Mt}$ on Georges Bank and $90.63 \mathrm{Mt}$ in the North Sea, values that exceed the assumed $S_{\max }$ of respectively 5 and $50 \mathrm{Mt}$, and the equilibrium biomass with no fishing of $4.2 \mathrm{Mt}$ and $22.9 \mathrm{Mt}$. The difference can be ascribed to not all the plankton and benthos being a suitable size for fish prey, and plankton and benthos having a lower energy content than fish (Dauvin and Joncourt 1989, Pedersen and Hislop 2001), such that a greater mass of invertebrates is required to satisfy the consumption of the fish species. Therefore the assumed biomass of forage species is not excessive.

Being satisfied with the predictions of selectivity impacts on two example communities, we now can ask how general these results are, and to what extent they can be generalized to other communities. Using a size spectrum model, Rochet and Benoît (Submitted) found that fishing selectively decreases size diversity more than fishing less selectively. Andersen and Pedersen (2010) developed a size- and trait- based model in which life-history is scaled by asymptotic length and predation is governed by length; they found that targeting all lifehistories would remove large fish while targeting more restricted sets of asymptotic lengths 
would create peaks and valleys in the size-spectrum. That we did not find such general results of the effects of size-selective fishing in the present study can probably be ascribed to the size-spectra being less regular here, which might be a more realistic description of actual size-spectra. Impacts of size-selectivity depend on the overlap between the size-selection curve and the community size-spectrum. The size spectrum will be depleted where it overlaps with the size-selection curve, and some top-down cascade might occur when fishing and biomass co-occur at medium to large sizes (Fig. 6). Depending on the shape of the "unfished" size-spectrum, it can be inferred how fishing selectivity will either improve its regularity (by depleting peaks), thus increasing size diversity, or decrease its slope and/or create additional crests or valleys, thereby decreasing size diversity.

The effects on species diversity however, depend on the species composition and size-range of each species. The result that selectively fishing large fish does not maximize biodiversity for a given level of catch is probably valid across a wide range of communities. A community that would not be impacted by the selective removal of the largest individuals would be either one with a peak in large sizes (which is unusual, as size spectra are generally decreasing, Kerr and Dickie 2001); or one with no fish at all in the large sizes, but in that case selectively fishing large fish would not yield anything. As for the result that fishing all species evenly affects biodiversity less than selectively targeting a restricted set of species, the pattern was consistent across the two communities and two fishing intensities $\left(F_{\text {full }}=0.4\right.$ and $F_{\text {full }}=0.8$ ). It is likely that targeting a particular combination of species with similar size-ranges and/or high dominance would affect biodiversity in a different way; however, as we focused on species selectivity that is, the number of species, and constructed random sets, these particular sets were diluted among all other sets of species. Thus it is probable that our species selection findings are quite general.

\subsection{Measuring biodiversity and fishing pressure}

These results are largely determined by the way we standardized fishing pressure across fishing scenarios, and by our choice of biodiversity measures. A simple measure of fishing pressure on an entire community is difficult to find. Average fishing mortality rate $F$ across species has been used in empirical analyses (e.g., Blanchard et al. 2005) and is roughly equivalent to the maximum fishing mortality rate in the present study. However, it cannot be used to compare the effects of different selectivity options; just as fishing mortality rates in single-stock models are comparable only for a given exploitation pattern. Our choice of total catch provides one measure of the ecosystem service provided by fisheries in units of the amount of food provided. This measure is appropriate if we consider that one objective of fisheries management is to maximize yield, under sustainability constraints. However, in fisheries that are not exploited solely to maximize food supply, the composition and value of the catch may be more important objectives and greater weighting may be given to larger and higher value species than smaller forage fish. Remarkably, the results of our alternate analyses that measured fishing pressure in units of total catch and total value were relatively consistent, despite $>10$ fold differences in the price of fishes sold for reduction and direct human consumption.

In the context of assessing the ecosystem effects of fishing, which is the main focus of this analysis, total catch may not be an equitable measure of fishing pressure on the community since the impact of a given catch of smaller species and size classes, where production and biomass are high, will be lower than the impact when the same catch is removed from larger size classes where production and biomass are lower. A differential weighting of sizeclasses would then be appropriate. We expected that using catch value instead of weight would account for this, but because price data were not size-dependent within species such a relationship was not apparent.

The choice of biodiversity metric, even if explicitly specified as a management objective, still requires a value decision. Our choice of two species diversity indices describing richness and evenness independently solves the balance between these two components implied by most combined indices (Magurran 2004). As expected, the effects of fishing selectivity were not 
the same on these two facets of biodiversity. Unselective fishing did not always result in the highest rate of species "collapses", while evenness was generally higher with unselective fishing. As for size diversity, our index values even size distributions with more weight given to large fish; we acknowledge that this weighting is arbitrary and that different indices would lead to different conclusions. Attempts to assess the effects of different management actions on progress towards an objective will always require that the objective is explicitly defined. Remarkably, few explicit objectives for biodiversity exist despite statements that high biodiversity is 'good' and high-level political aspirations to conserve biodiversity (Greenstreet, 2008). In practice, the few existing and explicit management objectives for biodiversity focus on the protection of rare and vulnerable species and habitats.

\subsection{How selectively should we harvest our oceans?}

So, should we think technologically, as heirs of a single-stock management perspective, and improve selectivity to reduce by-catch and protect biodiversity? Or should we think ecologically and, considering fishing impacts on the community level, fish evenly to preserve ecosystem structure and function? The latter idea is not new. For example, Caddy and Sharp (1986) proposed a "utopian" exploitation strategy, which consisted of fishing each species in proportion to the rate of natural predation it is subjected to; more recently Fowler (1999) similarly suggested determining exploitation rates based on consumption rates by natural predators. In the same vein, Larkin (1977) conjectured that a preferable technique of harvesting ecosystems would be to take the same proportion of everything above a certain size. Fogarty and Murawski (1998) thought that this type of broad harvesting pattern at low exploitation rates would entail a lower risk of altering ecosystem structure. Based on literature review of fishing impacts on tropical reef ecosystems, Jennings and Polunin (1996) suggested that harvesting a range of animals from various trophic groups might produce high yields without initiating ecosystem shifts. Besides these broad intuitions, is more accurate theory or empirical evidence available?

It seems difficult to provide a general answer to the question. While a size-spectrum model (Rochet and Benoît Submitted) showed that selectively fishing large fish might jeopardize the system stability and decrease its size diversity, the present study suggests that the actual effects of size-selectivity will depend on the overlap between the selection curve and initial size-spectrum in the community, that is, on the particular combination of gear selectivity, fishing intensity, and ecological settings in a given fishery. As for species selectivity, the general answer provided here that wide target sets are more conservative than narrower ones might be of little practical application. Fishing gears will catch together species with similar behaviors, which may consequently have related ecological functions; thus, not all species subsets are equally probable, and the random selection of fixed-size subsets may be too vague an approach to this problem.

A general answer might be of little use and more detailed, system-specific studies may be required. However, the results of such studies still very much depend on their choice of the measure of impact at the community or ecosystem level and the relationships between fished species and other components of the ecosystem. For example, McClanahan (1995) developed a coral reef ecosystem model to investigate the effects of various fishing patterns on yields, production and coral growth. He found that fishing everything would reduce total yield at low fishing intensity while targeting only piscivores would prevent high yields; only a strategy targeting both piscivores and herbivores but avoiding invertebrate feeders preserved high yields, high productivity and biodiversity. Other studies have used mass-balance models: Bundy et al. (2005), starting from the assumption that balanced exploitation would minimize ecosystem disturbance, used an index that measured the impact on relative biomass at different trophic levels. For the Gulf of Thailand fishery, they found that the highest impact resulted from the heavy exploitation of high trophic levels and the lowest from targeting low trophic levels, while the impact of balanced exploitation would be intermediate. In a Mediterranean trawl fishery Coll et al. (2008) found that total system biomass was insensitive to improved gear selectivity, while a biodiversity index (including only high trophic 
level species) would increase. There is no general answer from these system-specific studies.

There is little evidence of the effects of changing fishing selectivity from field studies. Bundy et al. (2005) found that the changes in exploitation balance and intensity on the eastern Scotian Shelf between 1970 and 2002 did not have the expected effects on ecosystem disturbance and ascribed this to lag effects and environmental changes. Increasingly, geartrial type studies describe the diversity of the catch and other multi-species metrics while comparing gears or mesh sizes. However, this amounts to describing the pressure exerted by various gears on the community. As for the resulting impact, both non-selective and selective fishing practices were found to be capable of modifying the structure of reef fish populations in a visual census comparison of 36 fishing grounds (Campbell and Pardede 2006). More studies that combine accurate assessments of both pressure and the structure of the community are needed.

Using a wide diversity of gears might be the way towards more balanced exploitation patterns (Bundy and Pauly 2001, Misund et al. 2002); since a variety of fisheries each selectively taking their preferred target species might, on aggregate, fish most parts of the food web. Alternatively, when unselective gears are used, by-catches are not necessarily harmful; but the use of those species that currently lack commercial value might be encouraged to minimize discarding (Clucas 1997). The model here did not consider how the recycling of discarded by-catch in the food-web might mitigate the effects of removals. Finally, little is known about selectivity by fishing gears from communities. Although predicted effects were highly dependent on the shape of the selection curve, we are ignorant of which one would be more appropriate in which circumstances. For the development of an ecosystem approach to fisheries, including exploitation strategies at the community scale, we need to expand our knowledge in this field.

In conclusion, which fishing selectivity conserves community biodiversity? Certainly the general statement that improving selectivity will protect biodiversity cannot be taken for granted, unless the focus of biodiversity conservation is solely on the status of a few rare or vulnerable species that can be avoided by improved selectivity. But the alternate statement that non-selective fishing conserves biodiversity better is not necessarily true either. Our analysis shows that any structured debate to inform management will need to be based on clear definitions of biodiversity and knowledge of the management objectives for biodiversity and the fishery.

\section{Acknowledgements}

We thank Michael Fogarty and Jason Link for their insights on the Georges Bank fish community, Richard Bell for providing the size-selection curves for Georges Bank, Eric Thunberg for providing the price data and the International Council for the Exploration of the Sea for providing survey data. SJ was supported by the UK Department of Environment, Food and Rural Affairs and MJR by the Pew Charitable Trusts. The opinions expressed are those of the authors and do not necessarily reflect the views of The Pew Charitable Trusts. JSC received a visiting scientist fellowship from IFREMER. We appreciate comments on the manuscript from Richard Bell and three anonymous referees.

\section{References}

Andersen, K.H., and Pedersen, M. 2010. Damped trophic cascades driven by fishing in model marine ecosystems. Proceedings of the Royal society London B 277: 795802.

Bellchambers, L.M., and de Lestang, S. 2005. Selectivity of different gear types for sampling the blue swimmer crab, Portunus pelagicus L. Fish. Res. 73: 21-27. 
Benoît, E., and Rochet, M.J. 2004. A continuous model of biomass size spectra governed by predation, and the effects of fishing on them. J. Theor. Biol. 226(1): 9-21.

Blanchard, J.L., Dulvy, N.K., Jennings, S., Ellis, J.R., Pinnegar, J.K., Tidd, A., and Kell, L.T. 2005. Do climate and fishing influence size-based indicators of Celtic Sea fish community structure? ICES Jounal of Marine Science 62(3): 405-411.

Branch, T.A., and Hilborn, R. 2008. Matching catches to quotas in a multispecies trawl fishery: targeting and avoidance behavior under individual transferable quotas. Can. J. Fish. Aquat. Sci. 65: 1435-1446.

Broadhurst, M.K. 2000. Modifications to reduce bycatch in prawn trawls: a review and framework for development. Rev. Fish Biol. Fish. 10: 27-60.

Broadhurst, M.K. 2008. Working laterally towards perfect selectivity in fishing gears. American Fisheries Society Symposium 49: 1303-1309.

Bundy, A., Fanning, P., and Zwanenburg, K.C.T. 2005. Balancing exploitation and conservation of the eastern Scotian Shelf ecosystem: application of a 4D ecosystem exploitation index. ICES J. Mar. Sci. 62: 503-510.

Bundy, A., Heymans, J.J., Morissette, L., and Savenkoff, C. 2009. Seals, cod and forage fish: A comparative exploration of variations in the theme of stock collapse and ecosystem change in four Northwest Atlantic ecosystems. Prog. Oceanogr. 81(1-4): 188-206.

Bundy, A., and Pauly, D. 2001. Selective harvesting by small-scale fisheries: ecosystem analysis of San Miguel Bay, Philippines. Fish. Res. 53: 263-281.

Caddy, J.F., and Sharp, G.D. 1986. An ecological framework for marine fishery investigations. FAO Fisheries Technical Paper 283, FAO, Rome.

Campbell, S.J., and Pardede, S.T. 2006. Reef fish structure and cascading effects in response to artisanal fishing pressure. Fish. Res. 79: 75-83.

Clarke, K.R., and Warwick, R.M. 1998. A taxonomic distinctness index and its statistical properties. Journal of applied ecology 35: 523-531.

Clucas, I. 1997. A study of the options for utilization of bycatch and discards from marine capture fisheries. FAO, Rome.

Coll, M., Bahamon, N., Sardà, F., Palomera, I., Tudela, S., and Suuronen, P. 2008. Improved trawl selectivity: effects on ecosystems in the South Catalan Sea (NW Mediterranean). Mar. Ecol. Prog. Ser. 355: 131-147.

Collie, J.S., Gifford, D.J., and Steele, J.H. 2009. End-to-end foodweb control of fish production on Georges Bank. ICES J. Mar. Sci. 66(10): 2223 - 2232.

Collie, J.S., and Rochet, M.J. 2010. Temporal Changes in the Diversity of Shelf-sea Fish Communities. ICES CM 2010 / Q:03.

Coull, K.A., Jermyn, A.S., Newton, A.W., Henderson, G.I., and Hall, W.B. 1989. Length/ weight relationships for 88 species of fish encountered in the north east Atlantic, Department of Agriculture and Fisheries for Scotland, Aberdeen.

Daan, N., Johnson, B., Larsen, J., and Sparholt, H. 1993. Analysis of the ray (Raja spec.) samples collected during the 1991 International Stomach Sampling project. ICES C.M. 1993 / G: 15: 18

Dauvin, J.-C., and Joncourt, M. 1989. Energy values of marine benthic invertebrates from the western English Channel. J. mar. biol. Ass. U.K. 69: 589-595.

Emmerson, M., and Raffaelli, D. 2004. Predator-prey body size, interaction strength and the stability of a real food web. J. Anim. Ecol. 73: 399-409.

Floeter, J., and Temming, A. 2005. Analysis of prey size preference of North Sea whiting, saithe, and grey gurnard. ICES J. Mar. Sci. 62: 897-907.

Fogarty, M.J., and Murawski, S.A. 1998. Large-scale disturbance and the structure of marine systems: fishing impacts on Georges Banks. Ecol. Appl. 8(1, Supplement): S6-S22.

Fowler, C.W. 1999. Management of multi-species fisheries: from overfishing to sustainability. ICES J. Mar. Sci. 56: 927-932.

Gislason, H. 1999. Single and multispecies reference points for Baltic fish stocks. ICES J. Mar. Sci. 56: 571-583. 
Gislason, H., Daan, N., Rice, J., and Pope, J.G. 2010. Size, growth, temperature and the natural mortality of marine fish. Fish Fish. DOI: 10.1111/j.1467-2979.2009.00350.x.

Greenstreet, S.P.R. 2008. Biodiversity of North Sea fish: why do the politicians care but marine scientists appear oblivious to this issue? ICES J. Mar. Sci. 65: 1515 - 1519.

Hall, M.A. 1996. On bycatches. Rev. Fish Biol. Fish. 6(3): 319-352.

Hall, S.J., Collie, J.S., Duplisea, D.E., Jennings, S., Bravington, M., and Link, J. 2006. A length-based multispecies model for evaluating community responses to fishing. Can. J. Fish. Aquat. Sci. 63: 1344-1359.

Hinke, J.T., Kaplan, I.C., Aydin, K., Watters, G.M., Olson, R.J., and Kitchell, J.F. 2004. Visualizing the food-web effects of fishing for tunas in the Pacific Ocean. Ecology and Society 9(1): 10.

Hjermann, D.Ø., Ottersen, G., and Stenseth, N.C. 2004. Competition among fishermen and fish causes the collapse of Barents Sea capelin. Proc. Natl Acad. Sci. USA 101(32): 11679-11684.

ICES. 2005a. Report of the Study Group on Multispecies Assessment in the North Sea (SGMSNS), 5-8 April 2005, ICES Headquarters ICES CM 2005/D:06, ICES, Copenhaguen.

ICES. 2005b. Report of the working group on the assessment of demersal stocks in the North Sea and Skagerrak (WGNSSK) ICES CM 2006/ACFM:09, ICES, Copenhagen.

Jennings, S., Greenstreet, S.P.R., and Reynolds, J.D. 1999. Structural change in an exploited fish community: a consequence of differential fishing effects on species with constrasting life histories. J. Anim. Ecol. 68: 617-627.

Jennings, S., and Polunin, N.V. 1996. Impacts of fishing on tropical reef ecosystems. Ambio 25(1): 44-49.

Jennings, S., and Revill, A.S. 2007. The role of gear technologists in supporting an ecosystem approach to fisheries. ICES J. Mar. Sci. 64: 1525-1534.

Jennings, S., Reynolds, J.D., and Mills, S.C. 1998. Life history correlates of responses to fisheries exploitation. Proc. R. Soc. Lond. B 265: 333-339.

Kerr, S.R., and Dickie, L.M. 2001. The biomass spectrum. A predator-prey theory of aquatic production. Columbia University Press, New York.

Larkin, P.A. 1977. An epitaph for the concept of maximum sustained yield. Trans. Am. Fish. Soc. 106(1): 1-11.

Lewison, R.L., Crowder, L.B., Read, A.J., and Freeman, S.A. 2004. Understanding impacts of fisheries bycatch on marine megafauna. Trends in Ecology \& Evolution 19(11): 598-604.

Mackinson, S., and Daskalov, G.M. 2007. An ecosystem model of the North Sea to support an ecosystem approach to fisheries management: description and parameterisation. Science Series Technical Report 142, Cefas, Lowestoft.

Magurran, A.E. 2004. Measuring biological diversity. Blackwell Publishing, Malden.

McClanahan, T.R. 1995. A coral reef ecosystem-fisheries model: impacts of fishing intensity and catch selection on reef structure and processes. Ecological Modelling 80: 1-19.

Millar, R.B., and Fryer, R.J. 1999. Estimating the size-selection curves of towed gears, traps, nets and hooks. Rev. Fish Biol. Fish. 9(1): 89-116.

Misund, O.A., Kolding, J., and Fréon, P. 2002. Fish capture devices in industrial and artisanal fisheries and their influence on management. In Handbook of Fish Biology and Fisheries. Volume 2: Fisheries. Edited by P.J.B. Hart and J.D. Reynolds. Blackwell Publishing, Oxford, UK. pp. 13-36.

Olin, M., Malinen, T., and Ruuhijärvi, J. 2009. Gillnet catch in estimating the density and structure of fish community-Comparison of gillnet and trawl samples in a eutrophic lake. Fish. Res. 96(1): 88-94.

Pedersen, J., and Hislop, J.R.G. 2001. Seasonal variations in the energy density of fishes in the North Sea. J. Fish Biol. 59: 380-389.

Pikitch, E.K., Santora, C., Babcock, E.A., Bakun, A., Bonfil, R., Conover, D.O., Dayton, P.K., Doukakis, P., Fluharty, D., Heneman, B., Houde, E.D., Link, J., Livingston, P.A., 
Mangel, M., McAllister, M.K., Pope, J.G., and Sainsbury, K.J. 2004. Ecosystembased fishery management. Science 305: 346-347.

Pinnegar, J.K., and Stafford, R. 2007. DAPTOM - An Integrated Database \& Portal for Fish Stomach Records. Database version 1.5. Phase 1, Final Report, October 2007. Available from www.cefas.co.uk/dapstom [accessed October 2008].

Polovina, J.J., Abecassis, M., Howell, E.A., and Woodworth, P. 2009. Increases in the relative abundance of mid-trophic level fishes concurrent with declines in apex predators in the subtropical North Pacific, 1996-2006. Fish. Bull. 107(4): 523-531.

Purvis, A., and Hector, A. 2000. Getting the measure of biodiversity. Nature 405: 212-219.

Rochet, M.-J., Benoît, E., and Collie, J.S. 2009. Is selective fishing more harmful to marine communities than even exploitation? Theoretical investigations. ICES CM 2009/M: 07.

Rochet, M.J., and Benoît, E. Submitted. Fishing destabilizes the biomass flow in the marine size spectrum.

Schindler, D.E., Essington, T.E., Kitchell, J.F., Boggs, C., and Hilborn, R. 2002. Sharks and tunas: fisheries impacts on predators with contrasting life histories. Ecol. Appl. 12(3): 735-748.

Segers, F.H.I.D., Dickey-Collas, M., and Rijnsdorp, A.D. 2007. Prey selection by North Sea herring (Clupea harengus), with special reference to fish eggs. ICES J. Mar. Sci. 64: 60-68.

Smith, B., and Wilson, J.B. 1996. A consumer's guide to evenness measures. Oikos 76: 7082.

Sparholt, H. 1990. An estimate of the total biomass of fish in the North sea. J. Cons. int. Explor. Mer 46(3): 200-210.

Springer, A.M., Estes, J.A., van Vliet, G.B., Williams, T.M., Doak, D.F., Danner, E.M., Forney, K.A., and Pfister, B. 2003. Sequential megafaunal collapse in the North Pacific Ocean: an ongoing legacy of industrial whaling? Proc. Natl Acad. Sci. USA 100(21): 12223-12228.

Steele, J.H., Collie, J.S., Bisagni, J.J., Gifford, D.J., Fogarty, M.J., Link, J.S., Sullivan, B.K., Sieracki, M.E., Beet, A.R., Mountain, D.G., Durbin, E.G., Palka, D., and Stockhausen, W.T. 2007. Balancing end-to-end budgets of the Georges Bank ecosystem. Prog. Oceanogr. 74: 423-448.

Tsou, T.-S., and Collie, J.S. 2001. Estimating predation mortality in the Georges Bank fish community. Can. J. Fish. Aquat. Sci. 58: 908-922.

Wells, R.J.D., Boswell, K.M., Cowan Jr., J.H., and Patterson, W.F. 2008. Size selectivity of sampling gears targeting red snapper in the northern Gulf of Mexico. Fish. Res. 89: 294-299.

Woodward, G., Ebenman, B., Emmerson, M., Montoya, J.M., Olesen, J.M., Valido, A., and Warren, P.H. 2005. Body size in ecological networks. Trends in Ecology \& Evolution 20(7): 402-409.

Worm, B., Hilborn, R., Baum, J.K., Branch, T.A., Collie, J.S., Costello, C., Fogarty, M.J., Fulton, E.A., Hutchings, J.A., Jennings, S., Jensen, O.P., Lotze, H.K., Mace, P.M., McClanahan, T.R., Minto, C., Palumbi, S.R., Parma, A., Ricard, D., Rosenberg, A.A., Watson, R., and Zeller, D. 2009. Rebuilding global fisheries. Science 325: 578-585.

Zhou, S. 2008. Fishery by-catch and discards: a positive perspective from ecosystem-based fishery management. Fish Fish. 9(3): 308-315. 


\section{Tables}

Table 1. Species-specific parameters used for North-Sea community. Parameter definitions are as follows: $k$ and $L_{\infty}$ are parameters of the von Bertalanffy growth equation; $L_{m a t}$ is length at maturity; $a$ and $b$ are coefficients of the weight $(\mathrm{g})$-length (cm) relationship; $S_{\max }$ is the maximum spawning stock biomass; $\phi_{i}$ indicates fished (1) and unfished (0) species. Sources: (Coull et al. 1989, ICES 2005b, Jennings et al. 1999, Jennings et al. 1998)

\begin{tabular}{|c|c|c|c|c|c|c|c|c|}
\hline Scientific name & Common name & $k\left(y r^{-1}\right)$ & $L_{\infty}(\mathrm{cm})$ & $L_{\text {mat }}(\mathrm{cm})$ & $a$ & $b$ & $\begin{array}{l}S_{\max } \\
\text { (tonnes) }\end{array}$ & $\phi_{i}$ \\
\hline & Forage species & 0.10 & 20 & 13 & 0.005 & 3.0 & $50 \times 10^{6}$ & $\overline{0}$ \\
\hline Sprattus sprattus & Sprat & 0.65 & 16 & 12 & 0.002112 & 3.4746 & 348307 & 1 \\
\hline Trisopterus minutus & Norway pout & 0.51 & 20 & 15 & 0.009200 & 3.0265 & 247644 & 0 \\
\hline Ammodytes spp & Sandeel & 0.90 & 22 & 11 & 0.001243 & 3.3200 & 1735847 & 1 \\
\hline Trisopterus esmarkii & Poor cod & 0.52 & 23 & 15 & 0.005180 & 3.1170 & 371336 & 1 \\
\hline Hippoglossoides platessoides & Long rough dab & 0.34 & 25 & 15 & 0.004400 & 3.2309 & 69720 & 0 \\
\hline Limanda limanda & $\mathrm{Dab}$ & 0.26 & 27 & 13 & 0.007400 & 3.1128 & 214644 & 0 \\
\hline Clupea harengus & Atlantic herring & 0.33 & 30 & 25 & 0.007420 & 3.0256 & 1759000 & 1 \\
\hline Trachurus trachurus & Horse mackerel & 0.19 & 34 & 19 & 0.003400 & 3.2943 & 25600 & 1 \\
\hline Microstomus kitt & Lemon sole & 0.42 & 37 & 27 & 0.025500 & 2.7643 & 35340 & 1 \\
\hline Solea vulgaris & Sole & 0.28 & 39 & 25 & 0.003600 & 3.3133 & 89700 & 1 \\
\hline Scomber scombrus & Mackerel & 0.36 & 40 & 26 & 0.003001 & 3.2900 & 155038 & 1 \\
\hline Merlangius merlangus & Whiting & 0.32 & 42 & 20 & 0.005180 & 3.1170 & 231716 & 1 \\
\hline Glyptocephalus cynoglossus & Witch flounder* & 0.20 & 44 & 29 & 0.001050 & 3.4950 & 26793 & 1 \\
\hline Eutrigla gurnardus & Gurnard & 0.16 & 46 & 23 & 0.006200 & 3.1003 & 97068 & 0 \\
\hline Pleuronectes platessa & Plaice & 0.11 & 54 & 27 & 0.021500 & 2.7901 & 441924 & 1 \\
\hline Amblyraja radiata & Starry ray & 0.23 & 66 & 46 & 0.040900 & 2.8965 & 215644 & 0 \\
\hline Melanogrammus aeglefinus & Haddock & 0.19 & 68 & 34 & 0.005580 & 3.1330 & 431386 & 1 \\
\hline Leucoraja naevus & Cuckoo ray & 0.11 & 92 & 59 & 0.038700 & 2.9591 & 12522 & 0 \\
\hline Lophius piscatorius & Monkfish & 0.18 & 106 & 61 & 0.015300 & 2.9979 & 15045 & 1 \\
\hline Gadus morhua & Atlantic cod & 0.23 & 123 & 70 & 0.006530 & 3.0970 & 181697 & 1 \\
\hline Pollachius virens & Pollock* & 0.07 & 177 & 55 & 0.010000 & 2.9620 & 291000 & 1 \\
\hline
\end{tabular}

* The North American common names are used for consistency with the Georges Bank fish community. 
Table 2. The food-web matrix for the 21 North-Sea species. Sources: (Daan et al. 1993, ICES 2005a, Pinnegar and Stafford 2007, Segers et al. 2007).

\begin{tabular}{|c|c|c|c|c|c|c|c|c|c|c|c|c|c|c|c|c|c|c|c|c|c|c|}
\hline & Predator & 1 & 2 & 3 & 4 & 5 & 6 & 7 & 8 & 9 & 10 & 11 & 12 & 13 & 14 & 15 & 16 & 171 & $18:$ & 19 & 20 & 21 \\
\hline & Prey species & & & & & & & & & & & & & & & & & & & & & \\
\hline 0 & Forage species & 0 & 0 & 0 & 0 & 1 & 1 & 1 & 1 & 0 & 0 & 1 & 1 & 1 & 1 & 1 & 1 & 1 & 1 & 1 & 1 & 1 \\
\hline 1 & Sprattus sprattus & 0 & 0 & 0 & 0 & 0 & 0 & 1 & 1 & 0 & 0 & 1 & 1 & 0 & 1 & 0 & 0 & 1 & 0 & 0 & 1 & 1 \\
\hline 2 & Trisopterus esmarkii & 0 & 0 & 0 & 0 & 0 & 0 & 0 & 1 & 0 & 0 & 1 & 1 & 0 & 1 & 0 & 1 & 1 & 1 & 1 & 1 & 1 \\
\hline 3 & Ammodytes spp & 0 & 0 & 0 & 0 & 0 & 1 & 1 & 1 & 0 & 0 & 1 & 1 & 0 & 1 & 1 & 1 & 1 & 1 & 0 & 1 & 1 \\
\hline 4 & Trisopterus minutus & 0 & 0 & 0 & 0 & 0 & 0 & 0 & 0 & 0 & 0 & 0 & 1 & 0 & 0 & 0 & 0 & 0 & 0 & 1 & 1 & 0 \\
\hline 5 & Hippoglossoides platessoides & 0 & 0 & 0 & 0 & 0 & 0 & 0 & 0 & 0 & 0 & 0 & 0 & 1 & 0 & 0 & 0 & 0 & 0 & 1 & 0 & 0 \\
\hline 6 & Limanda limanda & 0 & 0 & 0 & 0 & 0 & 0 & 0 & 0 & 0 & 0 & 0 & 0 & 0 & 0 & 0 & 1 & 0 & 1 & 1 & 1 & 0 \\
\hline 7 & Clupea harengus & 0 & 0 & 0 & 0 & 0 & 0 & 0 & 1 & 0 & 0 & 1 & 1 & 0 & 0 & 0 & 1 & 0 & 1 & 0 & 1 & 1 \\
\hline 8 & Trachurus trachurus & 0 & 0 & 0 & 0 & 0 & 0 & 0 & 0 & 0 & 0 & 1 & 1 & 0 & 1 & 0 & 0 & 0 & 1 & 1 & 1 & 1 \\
\hline 9 & Microstomus kitt & 0 & 0 & 0 & 0 & 1 & 0 & 0 & 0 & 0 & 0 & 0 & 0 & 0 & 0 & 0 & 0 & 0 & 0 & 1 & 0 & 0 \\
\hline 10 & Solea vulgaris & 0 & 0 & 0 & 0 & 0 & 0 & 0 & 0 & 0 & 0 & 0 & 0 & 0 & 0 & 0 & 0 & 0 & 1 & 1 & 0 & 0 \\
\hline 11 & Scomber scombrus & 0 & 0 & 0 & 0 & 0 & 0 & 0 & 0 & 0 & 0 & 0 & 1 & 0 & 0 & 0 & 0 & 0 & 1 & 1 & 1 & 1 \\
\hline 12 & Merlangius merlangus & 0 & 0 & 0 & 0 & 0 & 0 & 0 & 1 & 0 & 0 & 0 & 1 & 0 & 0 & 0 & 1 & 0 & 1 & 1 & 1 & 1 \\
\hline 13 & Glyptocephalus cynoglossus & 0 & 0 & 0 & 0 & 0 & 0 & 0 & 0 & 0 & 0 & 0 & 0 & 0 & 0 & 0 & 0 & 0 & 0 & 1 & 0 & 0 \\
\hline 14 & Eutrigla gurnardus & 0 & 0 & 0 & 0 & 0 & 0 & 0 & 0 & 0 & 0 & 0 & 0 & 0 & 0 & 0 & 0 & 0 & 0 & 0 & 1 & 0 \\
\hline 15 & Pleuronectes platessa & 0 & 0 & 0 & 0 & 0 & 0 & 0 & 0 & 0 & 0 & 0 & 0 & 0 & 0 & 0 & 0 & 0 & 0 & 1 & 0 & 0 \\
\hline 16 & Amblyraja radiata & 0 & 0 & 0 & 0 & 0 & 0 & 0 & 0 & 0 & 0 & 0 & 0 & 0 & 0 & 0 & 0 & 0 & 0 & 0 & 0 & 0 \\
\hline 17 & Melanogrammus aeglefinus & 0 & 0 & 0 & 0 & 0 & 0 & 0 & 1 & 0 & 0 & 1 & 1 & 0 & 1 & 0 & 0 & 1 & 0 & 1 & 1 & 1 \\
\hline 18 & Leucoraja naevus & 0 & 0 & 0 & 0 & 0 & 0 & 0 & 0 & 0 & 0 & 0 & 0 & 0 & 0 & 0 & 0 & 0 & 0 & 0 & 0 & 0 \\
\hline 19 & Lophius piscatorius & 0 & 0 & 0 & 0 & 0 & 0 & 0 & 0 & 0 & 0 & 0 & 0 & 0 & 0 & 0 & 0 & 0 & 0 & 0 & 0 & 0 \\
\hline 20 & Gadus morhua & 0 & 0 & 0 & 0 & 0 & 0 & 0 & 0 & 0 & 0 & 1 & 1 & 0 & 1 & 0 & 1 & 0 & 1 & 1 & 1 & 1 \\
\hline 21 & Pollachius virens & 0 & 0 & 0 & 0 & 0 & 0 & 0 & 0 & 0 & 0 & 0 & 0 & 0 & 0 & 0 & 0 & 0 & 0 & 1 & 0 & 0 \\
\hline
\end{tabular}

Diet of Monkfish and Sole unavailable for North Sea, borrowed from Celtic Sea. Diet of Cuckoo ray incomplete, borrowed from Starry ray for items not available. 
Table 3. Parameters of the size-selection curves for the nine fishing scenarios simulated in the model.

\begin{tabular}{ccccccc}
\hline Target / & \multicolumn{2}{c}{ Bell-shaped, selective } & \multicolumn{2}{c}{ Bell-shaped, non-selective } & \multicolumn{2}{c}{ S-shaped } \\
bound & $\sigma_{F}$ & $\mu_{F}(\mathrm{~cm})$ & $\sigma_{F}$ & $\mu_{F}(\mathrm{~cm})$ & $\eta$ & $L_{F 50}(\mathrm{~cm})$ \\
\hline Small & 9 & 25 & 25 & 25 & 0.25 & 15 \\
Medium & 9 & 50 & 25 & 50 & 0.1 & 40 \\
Large & 9 & 75 & 25 & 75 & 0.25 & 65 \\
\hline
\end{tabular}


Table 4. Summary of size-selectivity simulation results. Predicted trends in community metrics in the North Sea (NS) and Georges Bank(GB) with increasing fishing mortality, under various fishing regimes ( $S$ small, $M$ medium, $L$ large). $\diamond$ increase $₫$ decrease unchanged $\cap$ dome-shaped $\cup U$-shaped. For bell-shaped selectivity, each metric varied in the same direction under selective and unselective fishing, but with different slopes. Superscript indicates fishing selectivity that maximizes each metric under the fishing regimes (U unselective, $S$ selective for bell-shaped selectivity; * for S-shaped selectivity). For S-shaped selectivity, the outcome depends on fishing intensity: entries in the table are for high $F_{\text {full }}(>0.7)$.

\begin{tabular}{|c|c|c|c|c|c|c|c|c|c|c|c|c|}
\hline \multirow[t]{2}{*}{ Metric } & \multicolumn{3}{|c|}{$\begin{array}{l}\text { NS, bell-shaped } \\
\text { selectivity }\end{array}$} & \multicolumn{3}{|c|}{$\begin{array}{l}\text { NS, S-shaped } \\
\text { selectivity }\end{array}$} & \multicolumn{3}{|c|}{$\begin{array}{l}\text { GB, bell-shaped } \\
\text { selectivity }\end{array}$} & \multicolumn{3}{|c|}{$\begin{array}{l}\text { GB, S-shaped } \\
\text { selectivity }\end{array}$} \\
\hline & $\mathrm{S}$ & $\mathrm{M}$ & $\mathrm{L}$ & $\mathrm{S}$ & $\mathrm{M}$ & $\mathrm{L}$ & $\mathrm{S}$ & $\mathrm{M}$ & $\mathrm{L}$ & $\mathrm{S}$ & $M$ & $\mathrm{~L}$ \\
\hline Evenness & $\cap^{U}$ & $\cap^{U}$ & $-U$ & $\cap$ & $\cap^{*}$ & - & $\unlhd^{U}$ & $\unlhd^{S}$ & $\unlhd^{S}$ & $\searrow$ & ऽ & $\unlhd^{*}$ \\
\hline Size diversity & ৯S & $\unlhd^{U}$ & $\unlhd^{S / U}$ & $u^{*}$ & 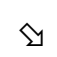 & $\searrow$ & $\diamond S / U$ & $\cap^{s}$ & $\varsigma^{U}$ & $\unlhd$ & $\unlhd^{*}$ & $\unlhd^{*}$ \\
\hline Total catch & $\cap^{u}$ & $\diamond U$ & $\diamond U$ & $\cap$ & $\cap^{*}$ & ৯ & $\diamond U$ & $\bowtie S$ & $\diamond U$ & $\cap^{*}$ & $\triangleright^{*}$ & ৯ \\
\hline $\begin{array}{l}\text { No species } \\
\text { collapsed }\end{array}$ & $\curvearrowright U$ & ¿ $\mathrm{S} / \mathrm{U}$ & - s $^{\mathrm{s}}$ & $2^{*}$ & $\diamond$ & - & $\diamond U$ & $\curvearrowright \mathrm{S} / \mathrm{U}$ & $\bowtie S$ & $\diamond^{*}$ & $\gtrsim$ & ৯ \\
\hline
\end{tabular}




\section{Figures}

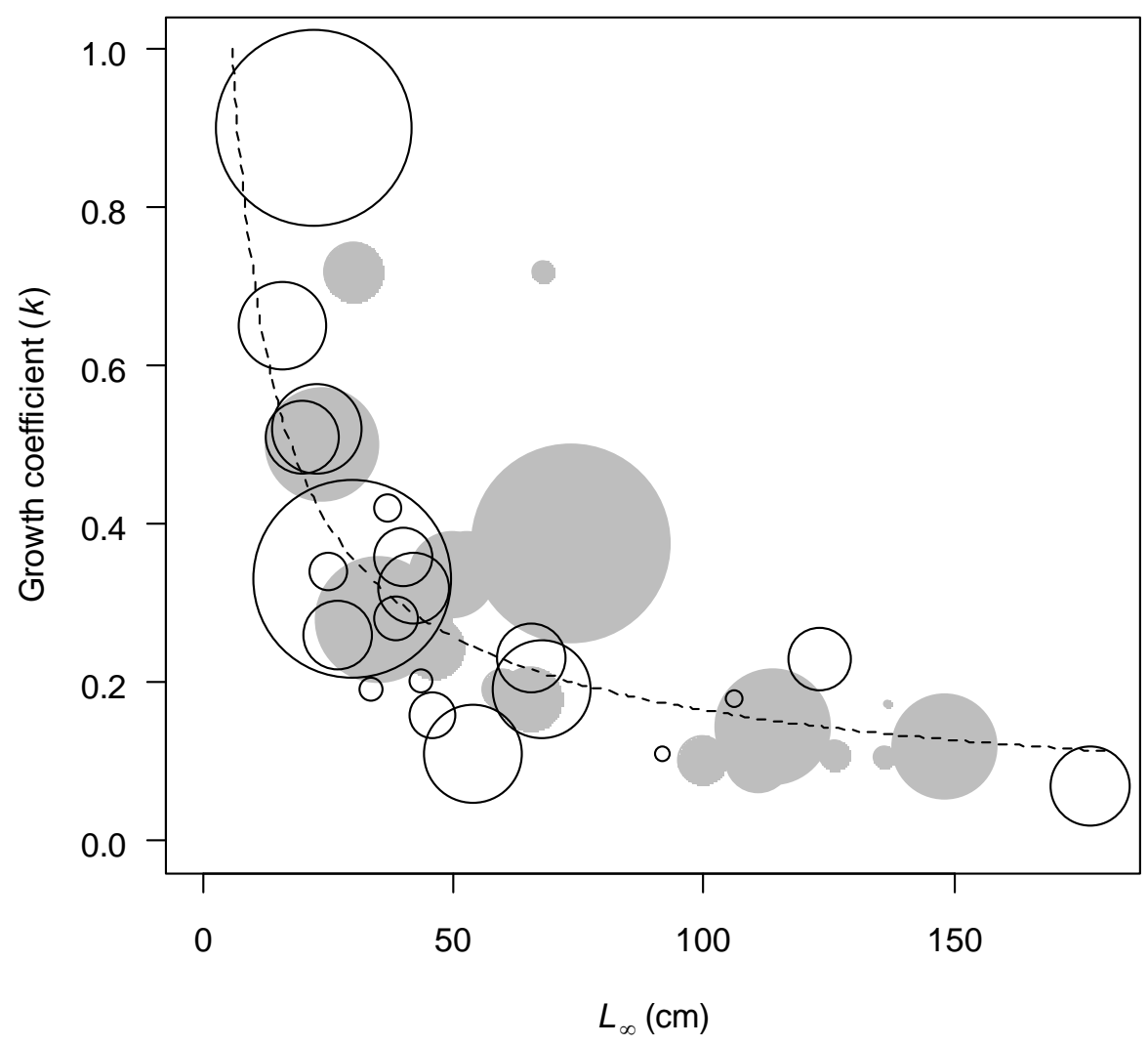

Figure 1

Figure 1. Relationship between the von Bertalanffy growth coefficient $(k)$ and asymptotic length $\left(L_{\infty}\right)$ among fish species on George Bank (shaded circles) and in the North Sea (empty circles). Circle area is proportional to the maximum biomass of each species $\left(S_{\max }\right)$. The broken line is the fitted relationship between $k$ and $L_{\infty}$ from Gislason et al. (2010). 
(a)
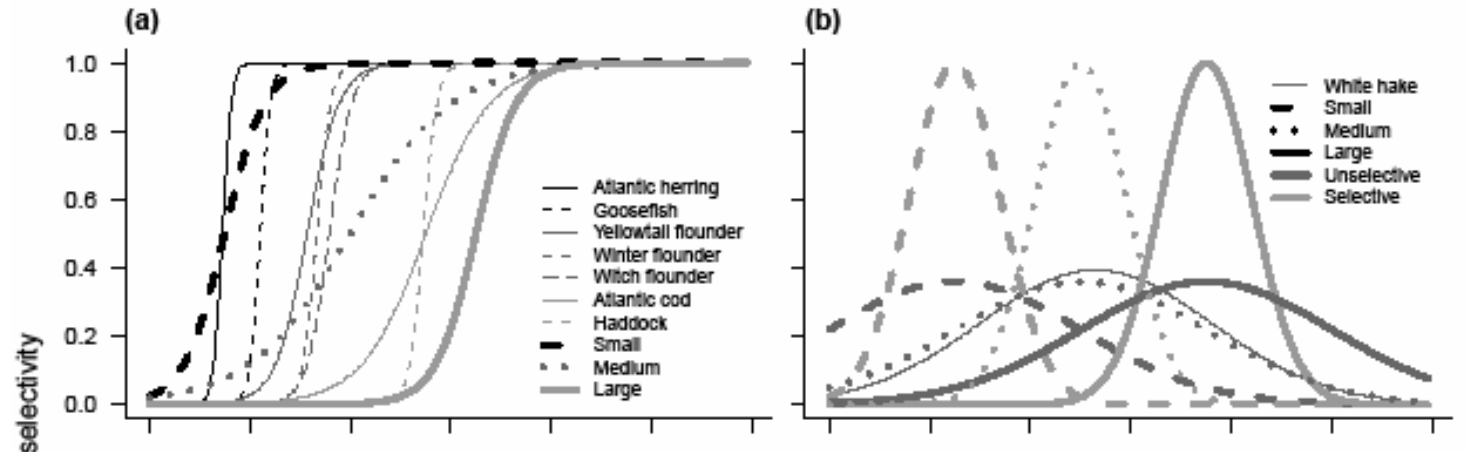$$
\text { 亭 }
$$

(c)

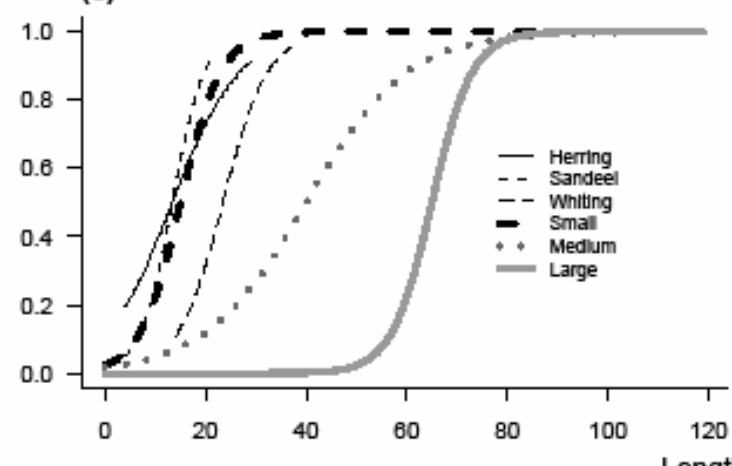

(d)

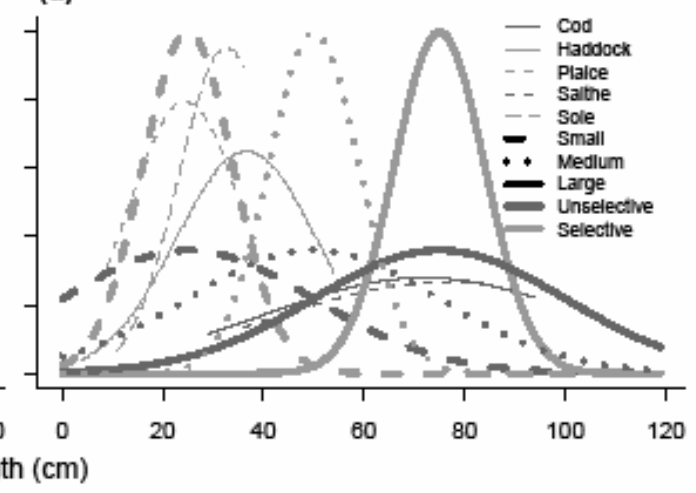

Figure 2

Figure 2. Size-selection curves simulated in the model (bold lines, see parameters in Table 3) compared with curves estimated empirically (thin lines) for Georges Bank (top) and North Sea (bottom) species. (a,c) S-shaped small, black; S-shaped medium, dark gray; S-shaped large, light gray; (b,d). Bell-shaped targeting small fish, dashed, medium fish, dotted, or large fish, solid selectively, light grey or unselectively, dark grey. 
(a)

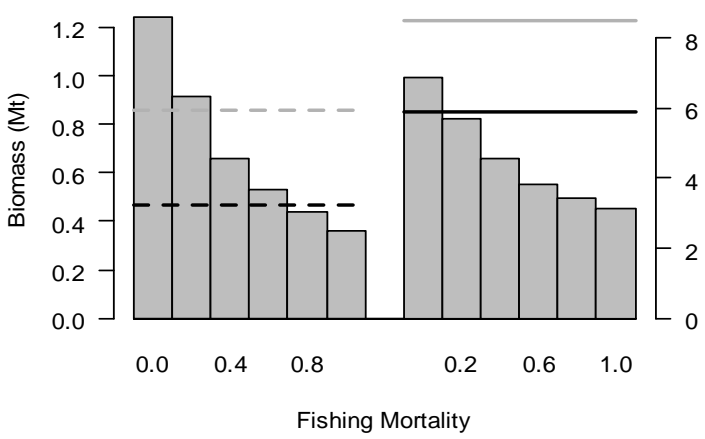

(c)

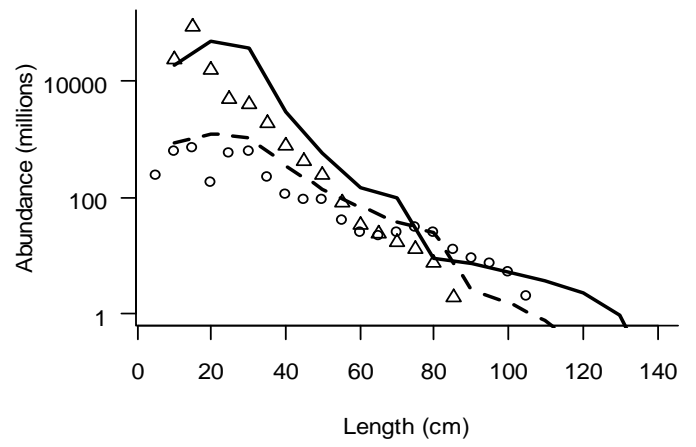

(b)

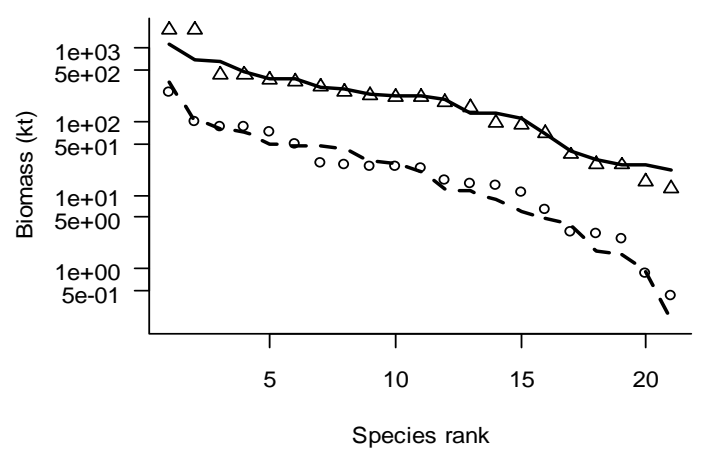

(d)

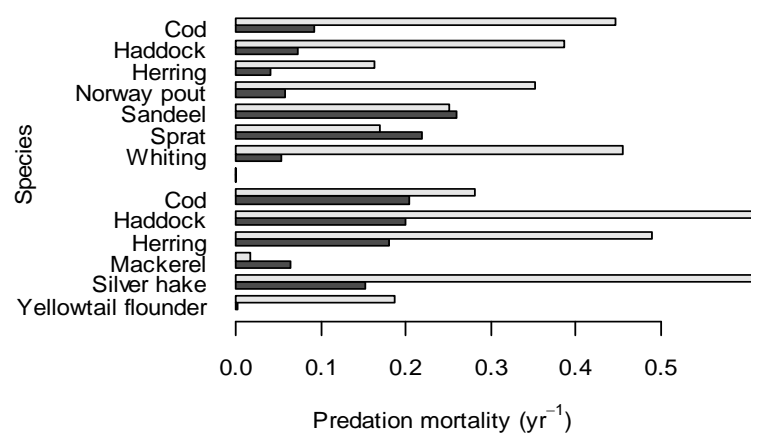

Figure 3

Figure 3. Key-run diagnostics for Georges Bank (dashed lines, open circles) and the North Sea (solid lines, triangles). (a) Total biomass of the fish community at six levels of fishing mortality ( $F_{\text {full, }}$, bars) compared with survey-derived biomass estimates (lines) for Georges Bank (left): averaged over 1963-2002 (grey) and 1963-1972 (black) and the North Sea (right): quarters 1 (black) and 3 (grey). (b) Ranked biomass of each species estimated by LeMANS with $F_{\text {full }}=0.2$ (lines) compared with the biomass estimates that were used to estimate the $\beta$ stock-recruit parameter (points). (c) Size spectra estimated by LeMANS with $F_{\text {full }}=0.2$ (lines) compared with average survey-derived size-spectra (points). (d) Average predation mortality for ages 0-1 estimated by LeMANS (black bars) and by MSVPA (grey bars) for (top) seven of the 21 North Sea species (ICES 2005a) and (bottom) six of the 21 Georges Bank species (Tsou and Collie 2001); Haddock $M_{2}=0.65$, Silver hake $M_{2}=1.44$. 

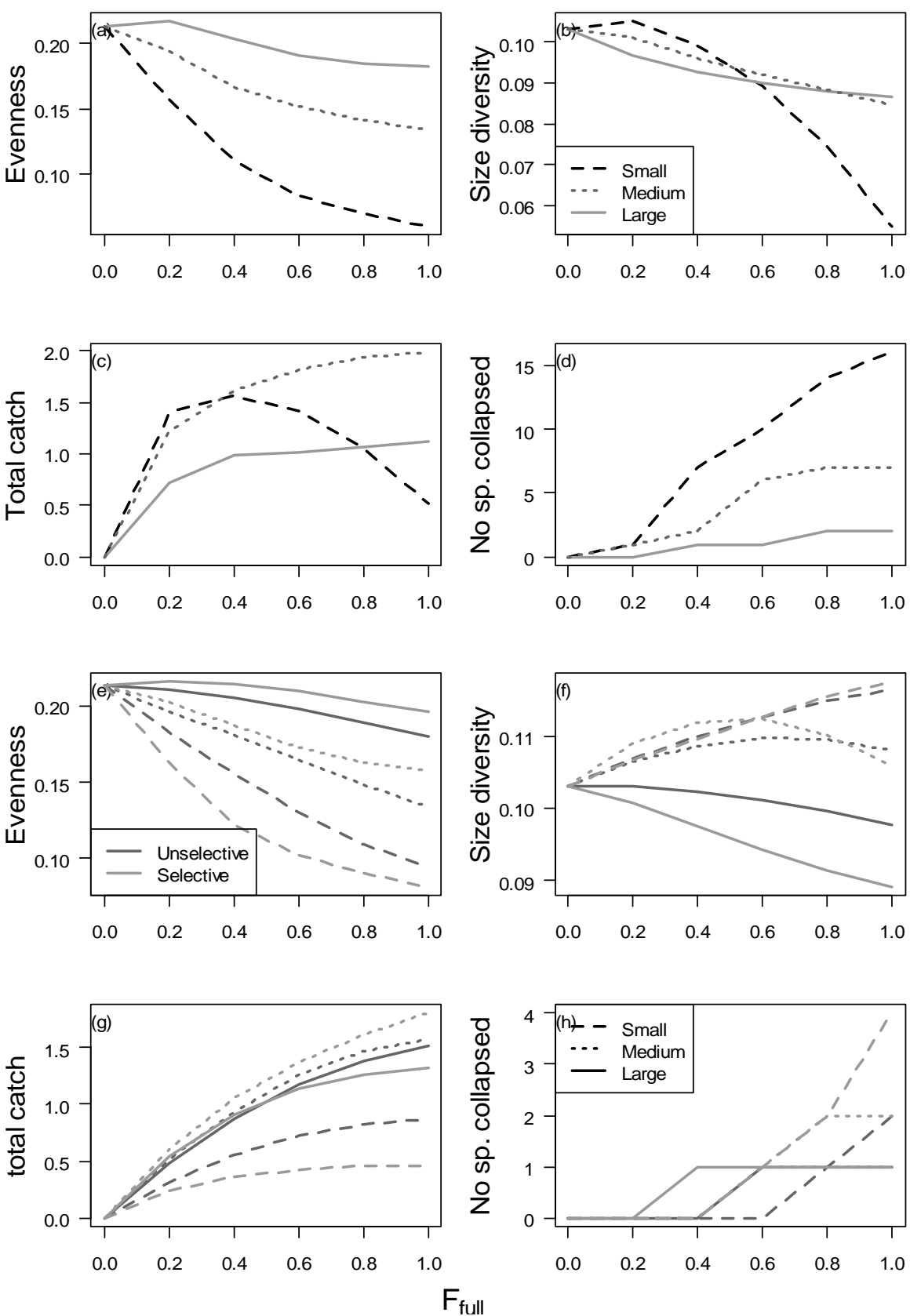

Figure 4

$F_{\text {full }}$

Figure 4. Effects of increasing fishing mortality on community metrics for Georges Bank when size-selectivity is S- (a-d) or bell-shaped (e-h). $F_{\text {full }}$ is fully recruited fishing mortality. Line types and colors of the selectivity curves as in Fig. 2. a,e) evenness, b,f) size diversity, $c, g$ ) total catch in hundred k-tonnes, $d, h$ ) number of species collapsed. 

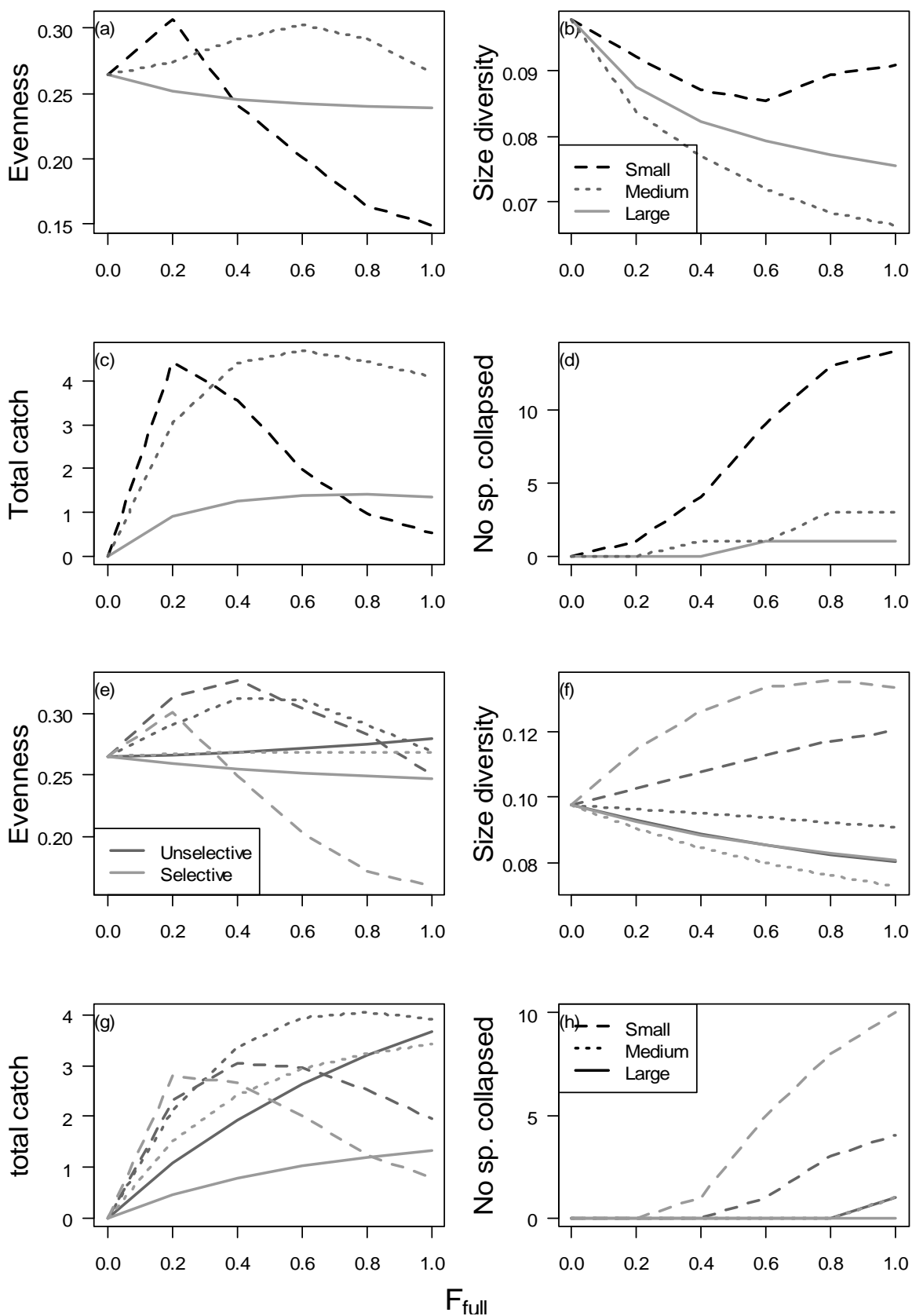

Figure 5

$F_{\text {full }}$

Figure 5. Effects of increasing fishing mortality on community metrics for the North Sea when size-selectivity is S- (a-d) or bell-shaped (e-h). $F_{\text {full }}$ is fully recruited fishing mortality. Line types and colors of the selectivity curves as in Fig. 2. a,e) evenness, b,f) size diversity, $\mathrm{c}, \mathrm{g}$ ) total catch in million tonnes, $d, h$ ) number of species collapsed. 


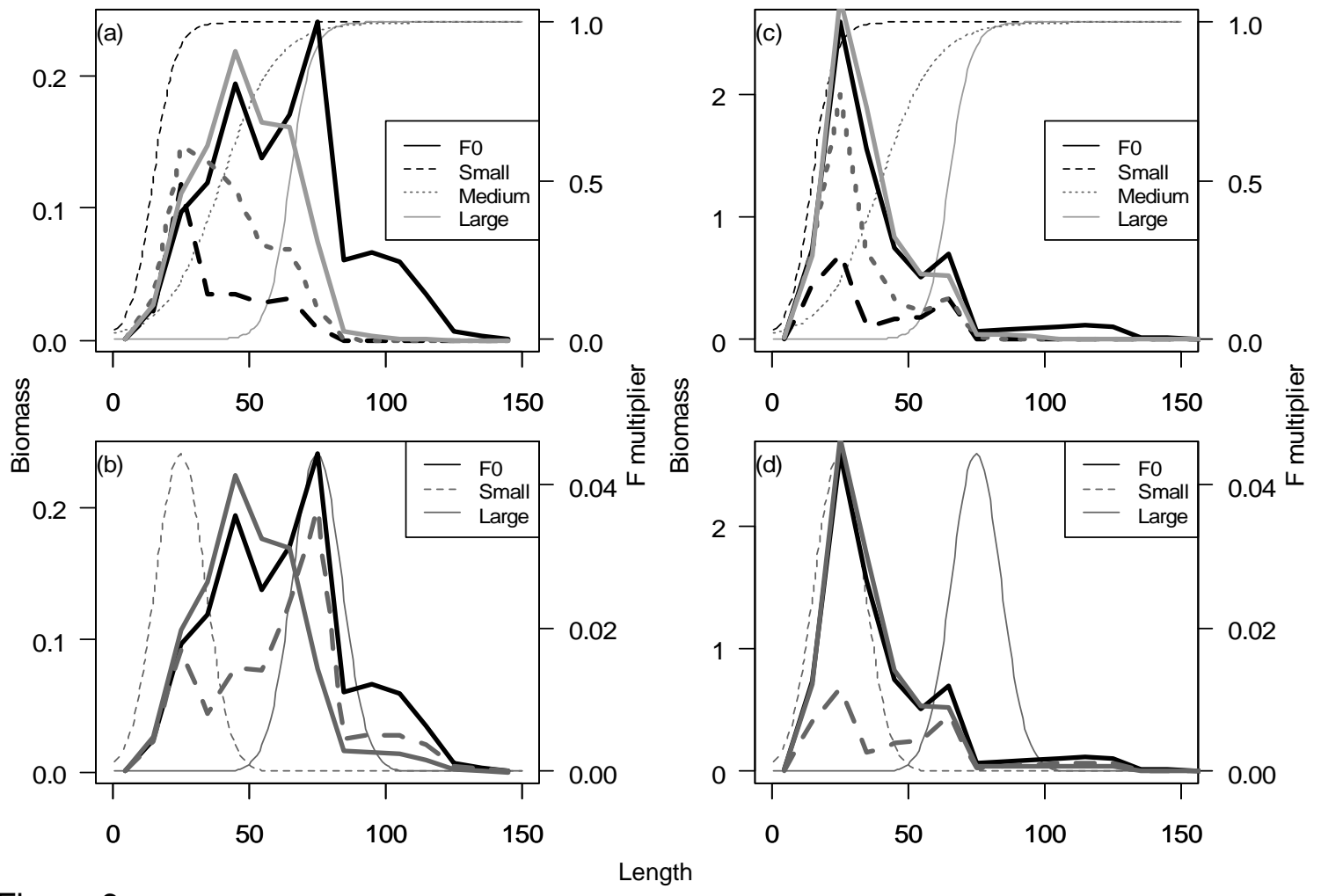

Figure 6

Figure 6. a,b) Georges Bank, c,d) North Sea biomass size-spectra of simulated communities with S- $(a, c)$ or bell-shaped $(b, d)$ selectivity. Biomass million tonnes. Bold lines show the biomass spectra in unexploited communities (black) or in communities fished with $F_{\text {full }}=0.8$ : Small selective fishing of small fish, Large selective fishing of large fish, S-shaped scenarios as in Table 1. Thin lines show the corresponding size-selection curves as in Fig. 2. 

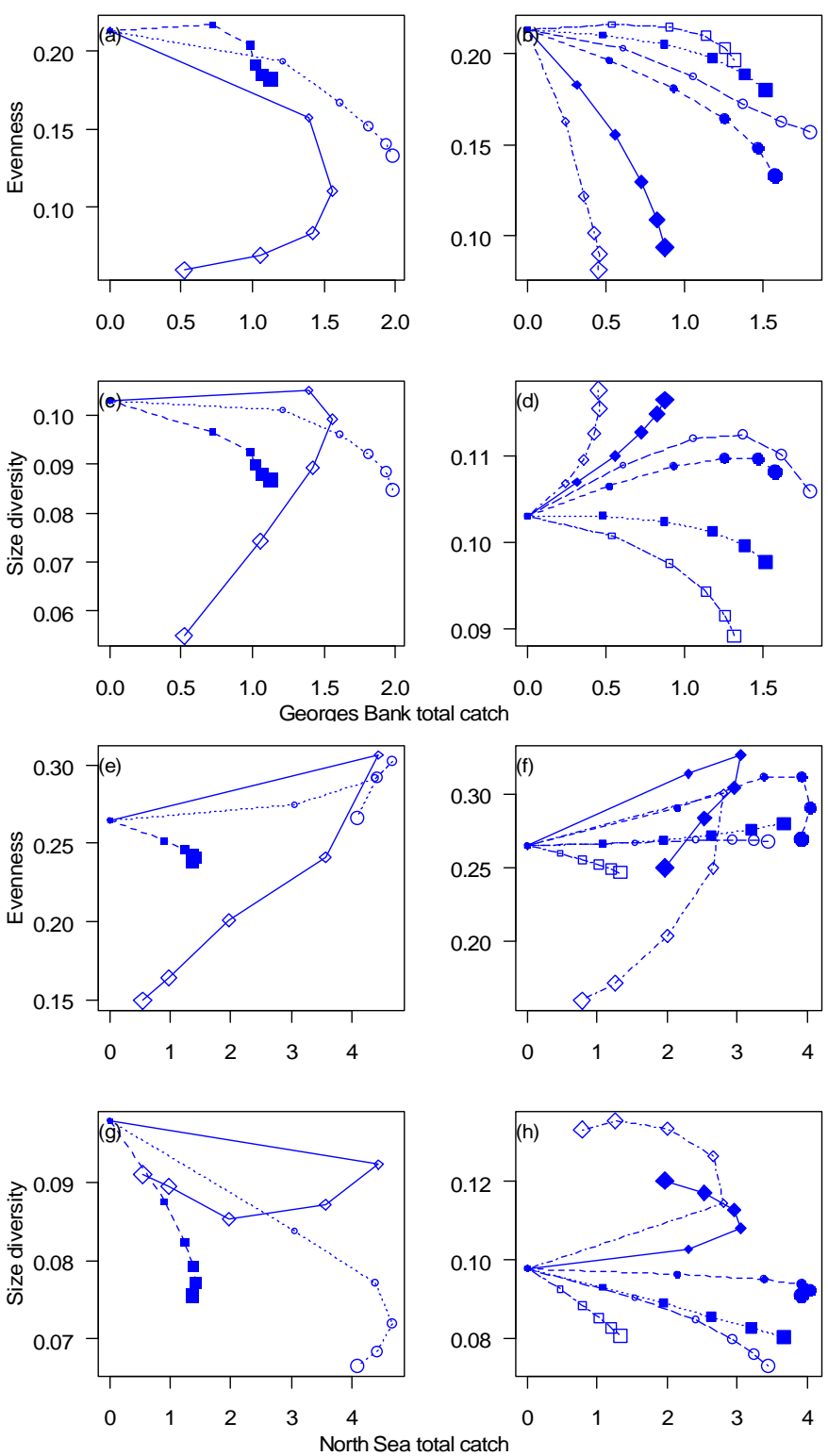

Figure 7

Figure 7. a-d) Georges Bank, e-h) North Sea evenness (a,b,e,f) and size diversity $(\mathrm{c}, \mathrm{d}, \mathrm{g}, \mathrm{h})$ for a given level of catch (in hundred k-tonnes for Georges Bank, million tonnes for the North Sea) when size-selectivity is $S-(a, c, e, g)$ or bell-shaped $(b, d, f, h)$. Full symbols: selective fishing, open symbols: unselective fishing. Targets / bounds: diamonds: small; circles: medium; squares: large, for selectivity parameters see Table 3. Symbol size increases with maximum fishing mortality at the community level (from 0.2 for the smallest to 1 for the largest symbols). 

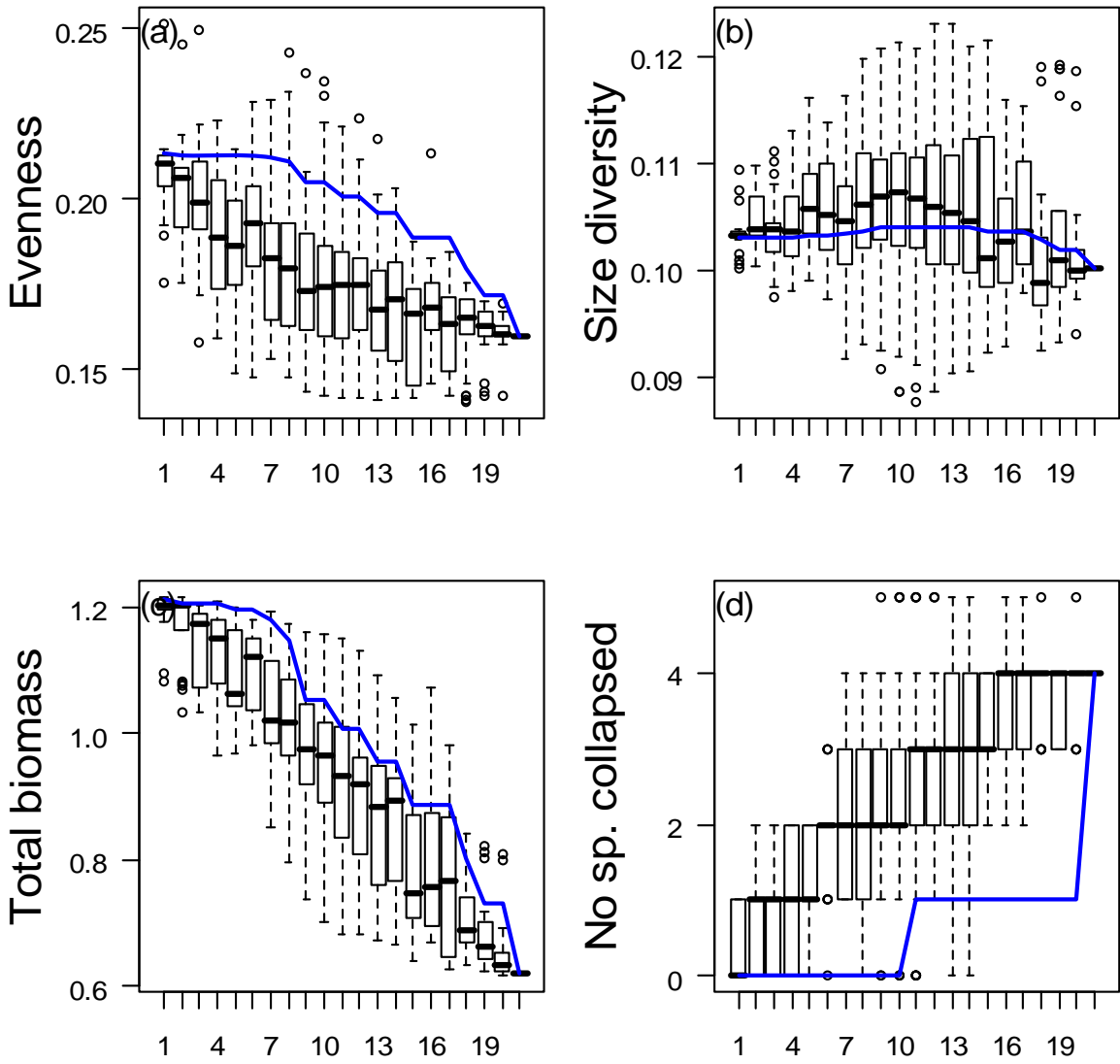

Figure 8

No species

Figure 8. Distribution of community metrics for Georges Bank versus number of species fished, where the target set is selected randomly, for $F_{\text {full }}=0.4$. The bold line is the reference level for unselective fishing, that is, the level of the metric that would be reached when catching the same amount (total catch weight) if all species were targeted. Box: inter-quartile range, bold line: median. a) evenness, b) size diversity, c) total biomass in million tonnes, d) number of species collapsed. 

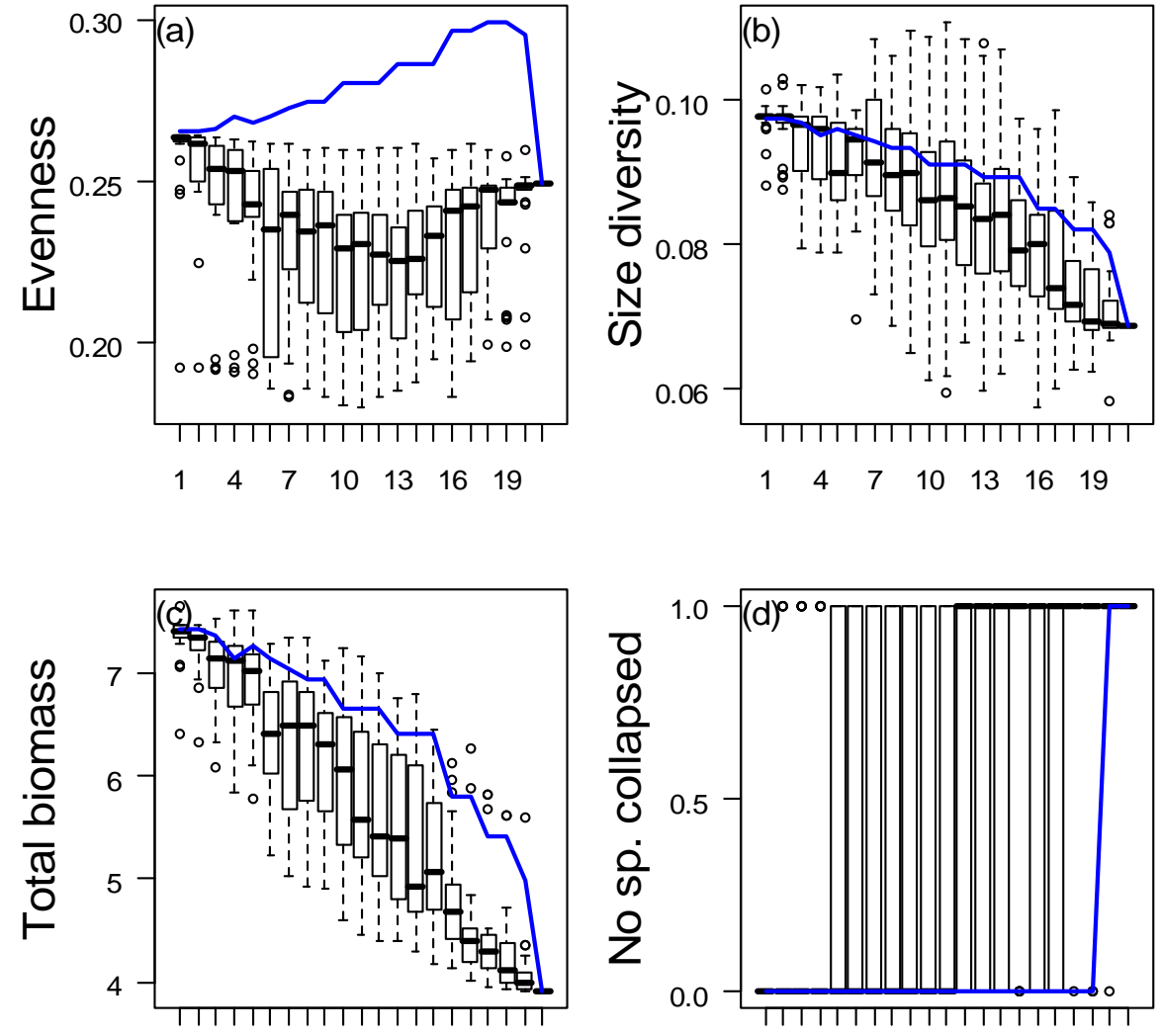

$\begin{array}{lllllll}1 & 4 & 7 & 10 & 13 & 16 & 19\end{array}$

$\begin{array}{lllllll}1 & 4 & 7 & 10 & 13 & 16 & 19\end{array}$

Figure 9

No species

Figure 9. Distribution of community metrics for North Sea versus number of species fished, where the target set is selected randomly, for $F_{\text {full }}=0.4$. The bold line is the reference level for unselective fishing, that is, the level of the metric that would be reached when catching the same amount (total catch weight) if all species were targeted. Box: inter-quartile range, bold line: median. a) evenness, b) size diversity, c) total biomass in million tonnes, d) number of species collapsed. 
Supplementary material to the manuscript 'Does selective fishing conserve community biodiversity? Predictions from a length-based multispecies model'

By Marie-Joëlle Rochet, Jeremy S. Collie, Simon Jennings and Stephen J. Hall
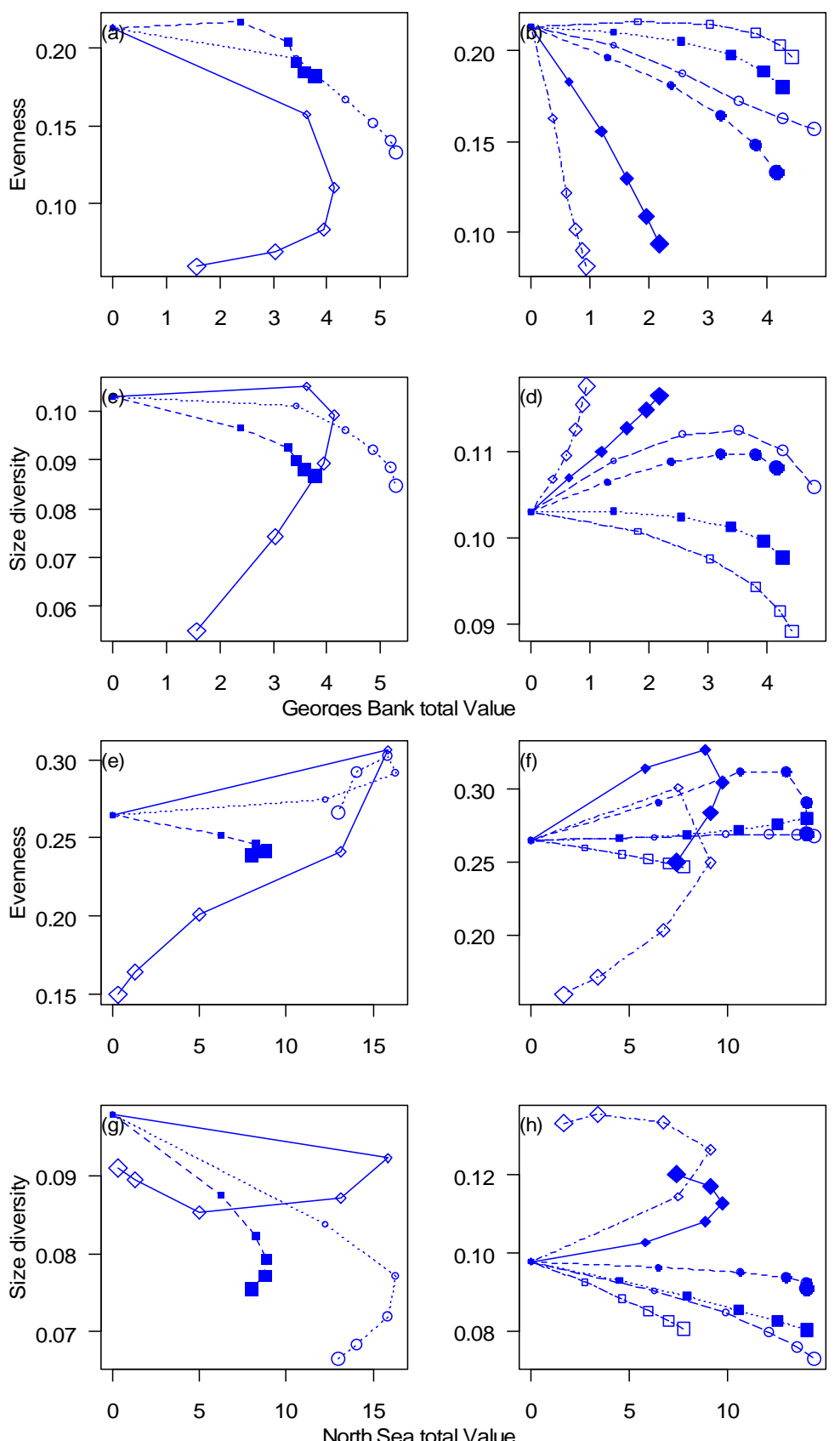

Figure S1. a-d) Georges Bank, e-h) North Sea evenness (a,b,e,f) and size diversity (c,d,g,h) for a given value of total catch (in hundred thousands USD (Georges Bank) or euros (North Sea)) when size-selectivity is S- $(a, c, e, g)$ or bell-shaped (b,d,f,h). Fishing scenarios (see Table 3): Full symbols: selective fishing, open symbols: unselective fishing; targets / bounds: diamonds: small; circles: medium; squares: large. Symbol size increases with maximum fishing mortality at the community level (from 0.2 for the smallest to 1 for the largest symbols). 